Accepted for publication in Biochimie

\title{
Protein contacts, inter-residue interactions and side-chain modelling.
}

\author{
Guilhem Faure ${ }^{1}$, Aurélie Bornot ${ }^{1} \&$ Alexandre G. de Brevern ${ }^{1 *}$ \\ ${ }^{1}$ INSERM UMR-S 726, Equipe de Bioinformatique Génomique et Moléculaire (EBGM), \\ Université Paris Diderot - Paris 7, case 7113, \\ 2, place Jussieu, 75251 Paris, France
}

Short title: protein contacts

* Corresponding author:

Mailing address: Dr. de Brevern A.G., Equipe de Bioinformatique Génomique et Moléculaire (EBGM), INSERM UMR-S 726, Université Paris Diderot - Paris 7, case 7113, 2, place Jussieu, 75251 Paris, France

E-mail : debrevern@ebgm.jussieu.fr

Tel: (33) 144277731

Fax: (33) 143263830 


\begin{abstract}
Three-dimensional structures of proteins are the support of their biological functions. Their folds are stabilized by contacts between residues. Inner protein contacts are generally described through direct atomic contacts, i.e. interactions between side-chain atoms, while contact prediction methods mainly used inter-C $\alpha$ distances. In this paper, we have analyzed the protein contacts on a recent high quality non-redundant databank using different criteria. First, we have studied the average number of contacts depending on the distance threshold to define a contact. Preferential contacts between types of amino acids have been highlighted. Detailed analyses have been done concerning the proximity of contacts in the sequence, the size of the proteins and fold classes. The strongest differences have been extracted, highlighting important residues.
\end{abstract}

Then, we studied the influence of five different side-chain conformation prediction methods (SCWRL, IRECS, SCAP, SCATD and SSCOMP) on the distribution of contacts. The prediction rates of these different methods are quite similar. However, using a distance criterion between side-chains, the results are quite different, e.g. SCAP predicts $50 \%$ more contacts than observed, unlike other methods that predict fewer contacts than observed. Contacts deduced are quite distinct from one method to another with at most $75 \%$ contacts in common. Moreover, distributions of amino acid preferential contacts present unexpected behaviors distinct from previously observed in the X-ray structures, especially at the surface of proteins. For instance, the interactions involving Tryptophan greatly decrease.

key words : amino acid; protein domain; side-chain side-chain interaction; hierarchical folding; protein stability; contact potential; structural class; structuresequence relationship; local protein structure; secondary structure, sidechain conformation, side-chain prediction. 


\section{Introduction}

Amino acids are the basic structural building units of proteins. They have very varied physico - chemical properties (see Figure $1[1,2]$ ). Inter-residue contacts are the cement of protein structures that control most of biological functions. Numerous research teams have analyzed the sequence - structure relationship for a better understanding of protein fold and to perform structural prediction from sequence. At a local level, secondary structure predictions have been a tremendous research area during the last three decades [3] the prediction rates reaching now $80 \%[4,5]$. Nonetheless, protein secondary structure prediction progress attains a plateau and prediction rates seem now close to their optimal limit. Secondary structure are also partially determined by tertiary factors [6]. A marginal part of the failures of secondary structure predictions may be attributed to the influence of long-range interactions [7]. Moreover, secondary structures focus on two kinds of regular local structures, i.e. helix and sheet, which compose only a part of protein backbones. The absence of assignment for an important proportion of residues has led to the emergence of new approaches based on local protein structure libraries called structural alphabets able to approximate all local protein structures [8-14]. This kind of approach has proven its relevance by enabling local structure prediction [13, 15], structural alignments [16-18] and the discovery of functional local structural motifs [19].

Nonetheless, few studies do take into account inter-residue interactions, e.g. [20]. Contacts in proteins can be of different nature. Hydrogen bonds are formed by the "sharing" of a hydrogen atom between two electronegative atoms such as $\mathrm{N}$ and $\mathrm{O}$, participate in the formation of regular secondary structures [21]. It has also been shown in many studies that even weak hydrogen bonds could be essential for inter-residue contacts [22-24]. Ionic bonds involve interactions between oppositely charged groups of a molecule, e.g. the positively charged basic side chains of Lysine and Arginine, and the negatively charged carboxyl groups 
of Glutamic and Aspartic acid [25]. Compared to these electrostatic forces and long-range interactions, van der Waals are weak forces (attractions or repulsions) and involve short-range interactions. The hydrophobic amino acids of a protein will tend to cluster together. It is mainly due to their escape from the hydrogen bonded water network in which the protein is dissolved. Hydrophobic regions of a protein will preferentially locate away from the surface of the molecule $[26,27]$.

Thus, inter-residue interactions have been one of the main focuses to understand the mechanisms of protein folding and stability [28-34]. Contact exploration in proteins could be of great interest from different perspectives, e.g. to develop potentials [35, 36], to identify amino acid side-chain clusters playing structural and / or functional roles [37-39] or to study dynamics of disordered regions of proteins [40]. For instance, different distributions of noncovalent interactions in proteins reflect their different environments, the extracellular and the intracellular ones [41]. Interestingly, inter-residue interactions can be characterized by contact order (CO) and long-range order (LRO) parameters that have a strong correlation with the folding rate of small proteins [42-45].

In the same way, many researches have been done to predict contacts from the sole knowledge of the sequence [46-54]. In spite of steady progresses, contact map prediction remains a largely unsolved challenge.

Protein structures can be seen as composed of single or multiple functional domains that can fold and function independently [55]. Dividing a protein into domains is useful for more accurate structure and function determination [55, 56, Taylor, 2007 \#181, 57]. Hence, methods for phylogenetic analyses and protein modelling usually perform better for single domains [58]. Automatic domain parsing generally makes the assumption that interdomain interaction (under a correct domain assignment) is weaker than the intradomain interaction (PUU [59], DOMAK [60] and 3Dee [61, 62], DETECTIVE [63], DALI [64], STRUDL [65], 
DomainParser [66, 67], Protein Domain Parser [68] and DDOMAIN [69]). These approaches maximize the number of contacts within a domain. Some authors have proposed alternative methods to hierarchically split proteins into compact units [70-76]. These folding units are supposed to fold independently during the folding process, creating structural modules which are assembled to give the native structure. In this way, we have developed a method called Protein Peeling [77] based on $\mathrm{C} \alpha$-contact matrix translated into contact probabilities.

Due to the low number of high-resolution protein structures available, protein computational modelling techniques are essential. Protein backbone local conformation could be designed using numerous approaches, e.g. homology modelling [78], threading [79], ab initio [80] and de novo approaches [81]. Side chain conformation prediction is also a difficult task $[82,83]$. Thus, different methods have been proposed to predict side chain conformations [84-88].

At this day, SCWRL is the most widely used method [89-91]. It is based on a simple scoring function and a backbone dependent rotamer library. The side chains positions are predicted by graph theory that decreases greatly the combinatory of possible positions [92]. The prediction accuracy for $\chi^{1}$ and $\chi^{1+2}$ dihedral angles is respectively $82.6 \%$ and $73.7 \%$. SCCOMP makes a scoring function based on terms for complementarities (geometric and chemical compatibility), excluded volume, internal energy based on probability of rotamers, and solvent accessible surface [93]. SCAP specificities lead to a four coordinate rotamer libraries [94]. The method used a CHARMM force field to perform a minimization. The principle of SCATD is related to SCWRL [95]. Its main difference relies on an optimisation of the graph theory search with a Goldstein criterion DEE to increase the quickness of the computation. Nonetheless, its accuracy is close to SCWRL. IRECS ranks all side-chain rotamers of a protein according to the probability with which each side chain adopts the respective rotamer conformation [96]. This ranking enables to select small rotamer sets. In a 
second step, worst effective energy rotamers are removed at each iteration.

In the present paper, we precisely analyse the impact of side chain coordinate prediction on protein contacts. The objective of this study is the analysis of contacts and especially in regards to prediction methods of side-chain conformations. Firstly, we present a classical study of contacts within proteins according to various criteria (lengths of proteins, SCOP classes, secondary structures, amino acid frequencies, accessibility). Secondly, these analyses are compared to the favoured contacts given by different side-chain replacement methods.

\section{Materials and Methods}

Dataset. A non-redundant protein databank has been initially built using PDB-REPRDB $[97,98]$. It was composed of 1,736 protein chains taken from the Protein DataBank (PDB) [99]. The set contained proteins with no more than $10 \%$ pairwise sequence identity. We selected chains with a resolution better than $2.5 \AA$ and a $R$-factor less than 0.2. Pairwise root mean square deviation $(r m s d)$ values between all chains were more than $10 \AA$. Only proteins with more than $99 \%$ of complete classical amino acids were conserved. Moreover, proteins that cannot be studied by software used during analysis process (see paragraph Analyses) have also been excluded. Thus, we retained 1,230 protein chains corresponding to 377,232 residues.

Contact definitions. Two residues are in contact if they are at a lower distance than a distance $\tau$ one to the other (cf. Figure 2). Thus, we analyze various distances: (1) $C_{\alpha}-C_{\alpha}$, noted $\mathrm{C} \alpha$, (2) $\mathrm{C}_{\beta}-\mathrm{C}_{\beta}$, noted $\mathrm{C} \beta$, (3) minimal distance between the heavy atoms of the protein backbone of the two residues, noted BB, (4) minimal distance between the heavy atoms of the side chains of the two residues, noted SC, (5) minimal distances between all the heavy atoms 
of two residues, noted ALL (cf. Figure 3). The distance criteria will be noted with the value of $\tau$ in superscript to facilitate the reading, e.g. for the $\mathrm{C} \alpha$ distance, a value of threshold $\tau$ equal to $8 \AA$ will be noted $C \alpha^{8}$. The threshold $\tau$ varies, in this study, between 4 and $20 \AA$. The interactions at short distance in the sequence are discarded, i.e. D/2 residues surrounding the studied residue will not be considered. $D$ is the main diagonal of the contact map, classical values have been used [100]. For Glycine, $\mathrm{C}_{\alpha}$ is used for $\mathrm{C}_{\beta}$ and side chain analyses.

Analysis of preferential contacts. Analysis of the observed contacts is carried out mainly by computing the relative contact frequency (noted $r f$ in the text) of the amino acid of type $i$ found in contact (distance lower than $\tau$ ) with the amino acid of type $j$ :

$$
r^{f} a a_{i j}^{\text {contact }}=\frac{f a a_{i j}^{\text {contact }}}{f^{D B} a a_{j}}
$$

with $r^{f} a a_{i j}^{\text {contact }}$ the frequency of the contacts of the amino acid of type $i$ with amino acid of type $j: f a a_{i j}^{\text {contact }}=N a a_{i j}^{\text {contact }} / N a a_{i}^{\text {contact }} ; N a a_{i j}^{\text {contact }}$ is the number of contacts between residues of types $i$ et $j$, and $N a a_{i}^{\text {contact }}$ the total number of contacts of amino acid of type $i$. This value is normalized by $f^{D B} a a_{j}$, the average frequency of amino acid of type $j$ in the studied protein databank.

Analyses. Residue accessibilities have been calculated with nAccess software (version 2.1.1) [101]. To analyze the potential influence of side chains replacement, software SCWRL 3.0 [92], IRECS 1.1 [96], SCAP package from JACKAL 1.5 [94], SCATD 1.2 [95] and SCCOMP [93] were used. Secondary structure assignment has been done using DSSP software (version 2000, CMBI). The eight states DSSP have reduced to the classical three states: the $\alpha$-helix state contains $\alpha, 3.10$ and $\pi$ - helices, the $\beta$-strand state contains only the $\beta$ - 
sheet and the coil state corresponds to everything else ( $\beta$-bridges, turns, bends, and coil). Default parameters were used for each software. Outputs were adapted accordingly. Proteins were characterized according to the manually assigned classes of SCOP all- $\alpha$, all- $\beta, \alpha / \beta$ and $\alpha+\beta$ [102]. The automatic categorization of Michie and co-workers was also used [103]. It defines 3 classes: $\alpha, \beta$ and others. The first one contains proteins having more than $40 \%$ of $\alpha-$ helices and less than $15 \%$ of $\beta$-sheets, the second less than $15 \%$ of $\alpha$-helices and more than $30 \%$ of $\beta$-sheets, the last being defined by default. All the data are available at our web site: http://www.ebgm.jussieu.fr/ debrevern/CONTACTS.

\section{Results}

The objective of this study is firstly to compare the different associations of amino acids defined by different distance criteria. In a second way, predictions of side-chain conformations are performed; deduced contacts between amino acids are then analyzed and compared to the results obtained with the true X-ray structures.

\section{Preliminary analyses: contacts within proteins.}

Distances used in classical approaches of contact prediction involve $\mathrm{C} \alpha$ (sometimes C $\beta$ ) with thresholds $\tau$ of 8,10 or $12 \AA[54,104]$ or definitions of Potentials of Mean Force [36]. Distances SC with lowest thresholds, e.g. $\tau=$ of 4 [105, 106] or $5.5 \AA$ [107], are used for more precise analyses of contacts. We tested five types of distances with $D=6$ residues as in $[77,108]$.

Global analysis. Figure 4 shows the distribution of the mean number of contacts. This value goes from less than 0.01 , with a distance $\mathrm{C} \alpha$ for a $\tau$ equals to $4 \AA$, to more than 45 for $\tau$ $=20 \AA$. Three groups of distance types come out from this figure: (1) the distances $\mathrm{C} \alpha$ and 
$\mathrm{C} \beta$ have close mean number of contacts, (2) the distances involving the protein backbone (BB) and the side chains (SC) have also rather close values, (3) the distance between all atoms of the residues (ALL) leads to much more contacts. This latter induces in average twice more contacts than $\mathrm{BB}$ and SC. For instance, for a $\tau$ value of $8 \AA$, the ratio $\mathrm{C} \beta$ / $\mathrm{C} \alpha$ is $1.2, \mathrm{SC}$ / $\mathrm{C} \alpha$ is 2.31 and $\mathrm{BB} / \mathrm{C} \alpha 2.30$ while ALL / $\mathrm{C} \alpha$ equals 4.17. Clearly, contacts involving protein backbones and side chains do not relate to the same residues. In addition, the calculation of ratio $\mathrm{ALL}^{4}$ on $\mathrm{C}^{8}$ gives a ratio less than 1 (0.77). In fact, the differences are much more important, only $58 \%$ of the pairs of amino acids considered by $\mathrm{ALL}^{4}$, are also found with $\mathrm{C} \alpha^{8}$ and conversely only $44 \%$ of the couples of amino acids considered by $\mathrm{C} \alpha^{8}$ are covered by $\mathrm{ALL}^{4}$. This proportion decreases to only $22 \%$, if the analysis relates to $\mathrm{SC}^{4}$ with $\mathrm{C} \alpha^{8}$. These results show that the parameters classically used for the prediction take into account a greater number of contacts than the ones considered for the analyses of preferential contacts, e.g. [106].

Analysis by amino acid type. Figure 4 gives an average vision of the number of contacts. Because of differences in size, volume or polarity (see Figure 1), the various types of amino acids have different distributions of the number of mean contacts. Moreover, these values vary according to the types of distances and the different $\tau$ values. We performed a hierarchical clustering on the 20 amino acid distributions of mean contact number (for the 5 types of distance and $\tau$ ranging from 4 to $20 \AA$ ). Three distinct classes were obtained: (1) D, E, R, K, Q, P, N, (2), G, S, A, T and (3) W, F, Y, V, C, I, L, M, H. These classes are very stable according to the distance used; only Histidine changes class when $\mathrm{C} \beta$ distance is considered. Hence, the average tendencies of the different types of amino acids are commonly found whatever the type of distance used. 
Accessibility. Residue solvent accessibility is defined as the percentage of residue surface being accessible to a solvent molecule, generally water [109]. Exposed residues (relative accessibility $>25 \%$ ) are thus mainly on the protein surface. Conversely, within the core of proteins, residues are buried. As expected, Figure 5 shows a strong correlation between amino acid accessibility and their mean numbers of contacts. For $\mathrm{C} \alpha^{8}$, Cysteine is the most buried amino acid (only exposed at 20\%) and has the greatest mean number of contacts, i.e. 5.5. This is clearly due to their propensity to form disulfide bonds and the constraints they impose in their close neighbourhood. Charged amino acids are found on the surface of proteins due to their hydrophilic properties. They have a lower mean number of contacts than those of other amino acid. It should be noted that Proline behaves similarly as to polar amino acids. These strong tendencies are also found with the $\mathrm{C} \beta$ and $\mathrm{BB}$ distances. For SC and ALL distances, the correlation is weaker. A clear distinction in two classes appears: (a) hydrophobic and large amino acids and (b) polar residues. This analysis corroborates the preceding results, the group (1) corresponds to charged amino acids, strongly accessible and having few contacts, the group (2) includes amino acids having a mean accessibility and a mean number of contacts, the group (3) gathers aromatic and aliphatic, buried amino acids with many contacts. Thus, even if the distributions of the average number of the contacts according to the type of distance vary, the general properties of amino acids are always found whatever the type of distance is.

Relative frequencies of amino acid contacts. This section handles with $\mathrm{C} \alpha^{8}$ data (see supplementary data 1 ). We have analyzed the 40 highest and 40 lowest $r f$ values. All amino acids have particularly high $r f$ values with Cysteine, i.e. an average value equals to 1.62 , thus 1.62 more frequent than expected. The most important $r f$ value is as expected Cysteine with itself (6 times more than random). The minimal $r f$ value with $\mathrm{C}$ concerns Arginine (R), it 
remains however important $(r f=1.22)$. The local constraint exerted by the disulphide bridge explains this phenomenon. About a quarter of Cysteine is associated to a disulphide bridge. Aromatic residues (W, Y and F) are found grouped together, with $r f$ values ranging between 1.23 and 1.50. Only one exception is the Tyrosine (Y) which has a weak $r f$ value with Tryptophan (1.18). Interestingly, Methionine (M) has also a strong affinity with Tryptophan (W) and Phenylalanine $(\mathrm{F})$, the two biggest amino acids $(r f=1.23)$. Glutamine $(\mathrm{Q})$ has a rather low average number of contacts, close to the values of charged amino acids. It has affinities with these two last aromatic residues ( $r f$ of 1.30 and 1.22). It is also associated Cysteine $(r f=1.38)$, but its association for 13 other types of amino acids is under represented. Proline (P) has few amino acid preferences; it favours association with aromatic residues, W and $\mathrm{Y}$, with $r f$ values of 1.33 and 1.24 respectively. The aromatic amino acids play a major role in the interactions between residues. Their large volume explains partially this behaviour from a statistical point of view, but their importance comes especially from their aromatic cycle, which is implied in electrostatic interactions, e.g., aromatic - aromatic interaction, cation - aromatic or anion - aromatic interaction.

Methionine $(\mathrm{M})$, Threonine $(\mathrm{T})$, Histidine $(\mathrm{H})$ and Asparagine $(\mathrm{N})$ are strongly in contacts with themselves. Moreover, T, $\mathrm{H}$ and $\mathrm{N}$ have no other preferential contacts ( $r f$ values ranging between 1.22 and 1.67). Glycine (G) is in preferential contact with Aspartate (D), Asparagine (N) and itself ( $r f$ ranging between 1.27 and 1.37). Serine (S) does not have a real preference, except the generic one with Cysteine $(r f=1.48)$.

Contacts with Valine (V) are under - represented for 14 of the 20 amino acids (not with $\mathrm{N}, \mathrm{D}, \mathrm{G}, \mathrm{H}, \mathrm{P}$ and $\mathrm{S}$ ). Valine is the amino acid having the most average number of contacts (after Cysteine) and one of most frequent (7\% of the databank). Alanine (A), Isoleucine (I), Leucine (L) and Valine (V) form frequent couples of contacting amino acids (on average $r f$ is 1.41 with a maximum for couple I-I with a $r f$ value of 1.70). Their association with 
Asparagine (N), Aspartate (D), Glutamine (Q), Glutamate (E) or Lysine (K) is not favoured as expected. Hydrophobic associations are thus one of the most important cements of the protein fold.

The negatively charged Aspartate (D) and Glutamate (E) have a strong repulsion for many residues (18 residues for $\mathrm{E}$ and 13 for $\mathrm{D}$ ), they are associated to positively charged residues (Arginine and Lysine). In an equivalent way, positively charged Arginine (R) and Lysine (K), have a strong repulsion for many residues (18 residues for $\mathrm{K}$ and 11 for $\mathrm{R}$ ) and are naturally associated residues of opposite charge (D and E). The inter-residue interactions between opposite charged amino acids are thus well found due to the importance of ionic interactions.

Analysis of contacts according to their proximity in sequence. We defined three zones of contacts: near (5 to 20 residues), far (21 to 50 residues) and very far (more than 50 residues) contacts. For this analysis and the ones which follow, we selected interactions having a difference of $r f$ higher than 0.2 compared to the values in complete databank. Each zone contains an equivalent number of protein contacts. Influence of distance in the sequence is clear (see Table 1). However, it does not imply critical modifications, no association privileged becomes unfavourable and conversely. For the near contacts in the sequence, Cysteines remain always the main amino acid. The aromatic ones (W, Y and F) prevail too; moreover, they have higher $r f$ values. Y, W, M, L and I have preferential contacts with F; P, F, M, K, L, I, E, Q and N with Y; and R, C, Q, G, Y, H, K, M, F, P, W and S with W. The hydrophobic character of Tryptophan thus seems to have more weight in near contacts compared to what is observed in the whole data bank $[110,111]$. Methionine has here also a strong affinity with Tryptophan and itself. The aliphatic (I, L and V) and charged residues (D, E, R, K) show the same characteristics as those observed for the complete databank. For other 
residues (T, H, G, N, S, Q, P and A), no privileged contacts are observed. The far contact analyses give different results. Cysteine contacts remain privileged by all residues. Aromatic residues (W, Y and F) have less privileged associations compared to the near contact case (3 to 4 preferential amino acids). Other amino acids have a higher number of amino acid types in privileged contacts. By observing far and very far contacts, three amino acids show a specific behaviour. Methionine for the far contacts is associated only with itself and for the very far contacts with itself, A, C, F, and V, and also with W and Y. Glycine which has few preferential contacts in the whole databank, is frequently associated with 7 amino acids for far contacts $(\mathrm{N}, \mathrm{D}, \mathrm{Q}, \mathrm{G}, \mathrm{H}, \mathrm{P}$ and $\mathrm{S})$ and 9 amino acids for very far contacts $(\mathrm{R}, \mathrm{N}, \mathrm{D}, \mathrm{Q}, \mathrm{G}, \mathrm{H}$, $\mathrm{P}, \mathrm{S}$ and T). Its small size, i.e. absence of side - chain, which makes possible drastic changes of orientation of the protein backbone, and its frequency in turns and loops [8], explains partially this result. Proline make privileged contacts only for the far contacts with Q, E and W [112]. The other residues have behaviours close to the ones observed in the complete databank.

Analysis according to the size of proteins. We defined four protein sizes: (a) $<150$ residues, i.e. small proteins, (b) $151-250$, (c) $250-400$ and (d) $>400$. For 52 couples of amino acids (out of 400 possible), a difference of $r f$ higher than 0.2 was observed corresponding 51 times to small protein class and 4 times to the other classes (see Table 2). It should be noted that small proteins represent only $10 \%$ of proteins in the databank and possess amino acid frequencies slightly different from it. Three main behaviours may be distinguished: (1) a reduction in the $r f$ which goes from a favoured association to an underprivileged one [12 cases], (2) a reduction in $r f$, but without inversion of tendency [12 cases] and (3) an increase of a favoured $r f$ [28 cases]. Among the 52 observations, Tryptophan was concerned 8 times, Cysteine 11 times, Histidine 6 times and Methionine 4 times. For 
small proteins, the strong change of $r f$ values for Cysteine may be due to the amino acid frequency change $(+50 \%$ in regards to the databank). In small proteins, the number of disulphide bridges is also more important, to maintain the protein fold. The interactions established with Tryptophan are reinforced, whereas its contact frequency is weaker (-5\%). Its associations with residues charged positively ( $\mathrm{K}$ and $\mathrm{R})$, Methionine $(\mathrm{M})$ and the other aromatic ones are accentuated.

Analysis according to class SCOP. Amino acids frequencies in protein SCOP classes (all $-\alpha$, all $-\beta, \alpha / \beta$ and $\alpha+\beta$ ) often strongly diverge from databank values; this phenomenon was not observed for the analysis on proteins size influence. Surprisingly, less $r f$ differences are found (see Table 3). Only $18 r f$ inversions are observed (change of favourable interactions to unfavourable one and reciprocally) and only 18 other changes are notable. These changes are not equally distributed between the various classes. Indeed 21 cases concern all- $\alpha$ class, $15 \alpha+\beta$ class, and, only 4 times the class all- $\beta$ and 3 the $\alpha / \beta$. This result is surprising because the all- $\beta$ class is the one for which the amino acid distribution is the most distant from the databank distribution. The amino acids implied in these changes are Tryptophan, 7 times, Cysteine, 8 times, Histidine, 6 times, Methionine, 4 times and in a more surprising way Proline, 5 times. Important variations of amino acid frequencies are observed between classes. Differences in contact distributions are not due to the effect of the occurrences, but clearly to a specialization of contacts according to the protein classes. The particular role of Proline is not exclusively due to its property of breaker, but also to specific interaction stabilizing property. Indeed, this amino acid being in connection mainly with polar residues. Proline has been often linked to stabilizing interactions of $\alpha$-helices, thus its behaviour in all- $\alpha$ class is comprehensible [113]. 
Various thresholds ( $\tau$ ) for various distance types. Precedent analyses used a $\mathrm{C}^{8}$ distance. However, this kind of distance and this distance threshold $\tau$ are not the only one used [107, 113]. In this study, $\tau$ has been increased from 4 to $20 \AA$ by steps of $2 \AA$. For $\mathrm{C} \alpha^{4}$, the number of contacts is close to 0 . From our reference, $\mathrm{C} \alpha^{8}$ until $\mathrm{C} \alpha^{20}$, no notable change of the tendencies of interactions between residues are observed. $r f$ values show a slow decrease towards random when the distance threshold $\tau$ increases. To assess the relevance of this observation, we have computed the difference between $r f$ for $\mathrm{C} \alpha^{8}$ and $r f$ for $\mathrm{C} \alpha^{20}$, and evaluated if the differences are correlated with the initial values of $r f$ of $\mathrm{C}^{8}$. It is also possible to simply compute the correlation between $r f$ for $\mathrm{C}^{8}$ and $r f$ for $\mathrm{C} \alpha^{20}$. Nonetheless, the first approach allows looking at the contacts that are specifically found at distance more than $8 \AA$ A. The excellent Pearson's correlation coefficient of $(P C C)$ of 0.94 shows that the correlation is obvious (see Figure 6). Only the Cysteine - Cysteine interaction decreases more strongly than the others, it passes from the high $r f$ value of 6.14 to 1.90 .

Comparison with SC highlights strong dissimilarities. Inter-residue interactions are different. The PCC between (A) the $r f$ of $\mathrm{C} \alpha^{8}$ and (b) those of $\mathrm{SC}^{4}$ is only equal to 0.52 . Naturally, the more the value of $\tau$ increases, the more $\mathrm{SC}^{4}$ values tend towards those of $\mathrm{C} \alpha^{8}$. For $\mathrm{SC}^{20}, P C C$ largely increased to 0.70 . Between $\mathrm{C}^{8}$ and $\mathrm{SC}^{4}$, the average of the $r f$ differences equals to 0.42 , and, more of the $2 / 3$ of interactions have a difference value higher than 0.20 , the threshold previously used for analysis. Aromatic residues (W, F and Y) and especially the Tryptophan have the most important $r f$ gains with $\mathrm{SC}^{4}$ (10 couples have gains more than one unit, for example $\mathrm{W}-\mathrm{W}$ passes from 1.50 to 2.88). Histidine - Histidine interaction, a well studied interaction [107], presents also an increase of the $r f$ value from 1.37 to 2.55. Cysteine - Cysteine interaction has a $r f$ value higher than 10. In contrast, Glycine is the residue which loses the most; 18 of the 20 amino acids which are in contacts with it are found among the 23 greater $r f$ lost, and the majority goes to unfavourable values. The absence 
of side chain of Glycine is an easy explanation. It is implied in changes of local topology, the number of stabilizing connections is thus weaker and it has the smallest volume. This assertion is corroborated by the reduction in the $r f$ value of Asparagine $(\mathrm{N})$ with Glycine $(\mathrm{G})$ from 1.29 to $0.66, \mathrm{~N}$ is known to interact with the polypeptide backbone $[114,115]$.

\section{Side-chain replacements.}

Contacts induced by side-chain conformation predictions. Homology modelling or de novo approaches, implies the use of prediction methods for placing the side chains [116]. We analyzed the influence of this type of approach on the distribution of the contacts, i.e. the validity of the approach in the context of contact prediction. Thus, we tested several different software : SCWRL, SCATD, IRECS, SCAP and SSCOMP. All these conformation prediction methods add side-chains to a protein backbone using backbone-dependent rotamer library. The library provides lists of $\chi^{1}-\chi^{2}-\chi^{3}-\chi^{4}$ values and their relative probabilities for residues at given $\varphi-\psi$ values. The methods explore these conformations to minimize side-chain-backbone clashes and side-chain-side-chain clashes. For instance, SCWRL represents the side-chains as graphs and used dead-end elimination step, based on the simple Goldstein criterion to determine reasonable clusters of rotamers [92]. Being presently, the most commonly used method, we have deeply analyzed its results. Moreover, this method is very fast.

All the side chains of the proteins of our databank have been repositioned. Only $0.6 \%$ of proteins can not be treated by SCAP and $1.1 \%$ by SCCOMP. Analysis of contacts distributions for these predicted side-chains was carried out for the distances C $\beta$ with $\tau=8 \AA$ and SC with $\tau$ equals to $4 \AA$. For $C \beta^{8}$, the new positions of the side chains by SCWRL involve a light reduction in the average number of contacts (5\% less). The contacts are rather close to those observed in the protein databank (92.8\% in common). Similar results are observed for IRECS, SCCOMP and SCATD. At the opposite, SCAP generates a higher number of contacts 
$(+22 \%)$.

With $\mathrm{SC}^{4}$, the number of contacts is smaller than found for the protein databank with most of the methods, i.e. between $-1.4 \%$ for SCCOMP and $-15.0 \%$ for IRECS (see Table 4). Only SCAP behaves very differently. It generates $53 \%$ more contacts than observed. We can also notice that computation time per proteins was greatly superior with this approach.

Interestingly, even if the prediction methods give roughly the same number of contacts, they predict different contacts. For instance, SCWRL prediction rate for angle $\chi^{1}$ position is quite good [92]. If we consider contacts, e.g. $\mathrm{SC}^{4}$, it is not the case; SCWRL has only $55 \%$ of common contacts observed in the protein databank. The difference is thus far from being negligible. An analysis carried out according to accessibility, shows that hidden residues are slightly better in concord (64\%) with $\mathrm{SC}^{4}$ than those exposed (49\%). This result corroborates well the data of the literature on the quality of the side chain predictions [84, 93]. All methods find between $55 \%$ and $65 \%$ of the contacts observed in the protein databank, but at most they share $3 / 4$ of them $(75.7 \%$ of contacts defined by SCWRL are found by IRECS, and $70 \%$ by IRECS are also observed by SCWRL). Even with SCAP, that have $53 \%$ more contacts than observed, finds only $59.6 \%$ of the true contacts and shares between $55.1 \%$ and $64.4 \%$ of the contacts find by the other prediction methods. Thus, the contacts predicted by the different methods are clearly not the same.

Amino acid contact preferences with side-chain conformation prediction methods. At a global level, few $r f$ variations before and after replacement are observed. However, some tendencies can be noticed. To evaluate the potential impact of these variations on the favoured protein contacts, the average difference between $r f$ values for $\mathrm{SC}^{4}$ have been computed and are shown in Table 5. These values are low; they range from 0.049 to 0.096 with the notable exception of SCAP for which difference values are comprised in the range from 0.210 to 
0.244. Strangely, most of the methods have higher average $r f$ value divergence with the protein databank (SCWRL 0.074, SCATD 0.096, SCAP 0.244 and SCCOMP 0.062) than between themselves. From this global point of view, SCWRL, SCATD, IRECS and SCCOMP seem to be quite equivalent and SCAP an outlier.

For SCWRL (see Table 6), the $r f$ of the charged interactions are weaker after replacement of side chains (more than 0.2 of difference with $\mathrm{SC}^{4}$ ). It is an important loss, but comprehensible as the exposed rotamers are more difficult to place. At the opposite, $r f$ of Cysteine - Cysteine interaction increases again. The weight of the "positioning" of the disulphide bridges can explain this observation. Lastly, the $r f$ of amino acids associated to Tryptophan strongly decreases (12 amino acids). W being the biggest amino acids, the prediction of its side-chain conformation is associated to an important 3D space. Thus, use of predicted side-chain position shows a limited number of differences in terms of preferential amino acid contacts. Nonetheless, all the interactions implicated in theses divergences are of major importance, and, theses variations of $r f$ are thus less negligible than at first sight.

SCCOMP amino acid contact $r f$ values are very close to the one of the protein databank. Only $16 r f$ values have a difference higher than 0.2 . These variations touch only overrepresented associations. Moreover, they are mainly the same associations as observed for SCWRL, i.e. 13 of the 16 variations are also found with SCWRL (see Table 4). Interestingly, the $r f$ values of Cysteine - Cysteine interaction is quite identical to the one of the protein databank, i.e. 12.95 vs. 12.96 .

IRECS has similar behaviours with $21 r f$ values having a difference higher than 0.2 with the protein databank and 14 found also by SCWRL. Its C-C $r f$ value is higher, i.e. 13.94. The divergences of amino acid associations already highlighted by SCWRL are higher with this method. These latter mainly impacts charged residues (D, E, R and K), e.g. R association with E goes from 1.76 for SCWRL to 2.09 for IRECS. 
Precise analysis of SCATD shows a high similarity with SCWRL results. Indeed, 23 of the 26 variations of SCWRL better than 0.2 (cf. Table 4) are also determined by SCATD.

SCAP is associated to the highest number of contacts and shows a high difference of $r f$ values from the protein databank and all positioning methods. SCAP has $37 \mathrm{rf}$ values variation higher than 0.5 in regards to the protein databank, 10 are inversions, 1 is an increase ( $r f$ value of $\mathrm{N}$ interaction with $\mathrm{E}$ climbs from 1.01 to 1.53 ) and others are diminution. Indeed, for the great majority of $r f$ values, SCAP values diminished with respect to the protein databank values, i.e. specificities are lost.

Analysis of $\mathrm{C} \beta^{8}$ for SCAP reinforces this analysis. Firstly, SCAP still generates a higher number of contacts $(+22 \%)$. Nonetheless, $99.6 \%$ of the native contacts are described by SCAP. Average divergence of $r f$ values is lower than previously seen for $\mathrm{SC}^{4}$, i.e. 0.037 and only 10 amino acid couples have $r f$ value deviation more than 0.2.

\section{Discussion}

Contact maps are a widely used approach to analyse protein structures, protein folding molecular dynamic simulations, to define coarse grain potentials or to superimpose protein structures [117-121]. This short survey on protein contacts with different views aims at: (i) analyzing different measures and distance thresholds. Indeed, analysis and prediction methods used sometimes very different measurements, and highlighting significant differences could give new insights for future works. Thus, our research has been done on a recent nonredundant protein databank. (ii) comparing different side - chain prediction methods. We have highlighted mainly two points. From a classical point of view, most-side chain prediction methods yield very similar results. Firstly, we show that according to a contact distance criteria it is not the case. Secondly, this last point has repercussion on the distribution 
of amino acid interactions.

Analysis of the protein databank shows that the increase of databank size does not influence the features examined, for instance, on accessibility [122]. The distribution of the average contact number is clearly dependent on atoms chosen as references. One of the most interesting results is the fact that contacts taken into account according to a given type of distance is not compulsorily taken into account by another one, e.g. only $22 \%$ of the contacts of $\mathrm{SC}^{4}$ are considered by $\mathrm{C} \alpha^{8}$. As we showed with reduced amino acid alphabets, the use of different definitions could lead to diverging results [123]. Distribution of the privileged interactions shows expected results, like the importance of Cysteine and of aromatic residues $[105,106,124-130]$. Specificities are found according to the distance in the sequence between residues in contact. Some differences are observed compared to the literature. For instance, our results are not directly in agreement with the results presented by Brocchieri and Karlin on near, far and very far range in the sequence [131]. Indeed, these authors studied the number of occurrence of contacts whereas we analyzed the preferences by the use of the relative frequencies. Thus, they did not see the significance of aromatic interactions for near contacts as it was shown in other studies [23]. A contrario, our observations on Tryptophan are in agreement with literature [106] as most studies on specific interactions between residues are mainly devoted to close side-chain interactions. Concerning influence of the protein sizes, only the small proteins have particular characteristics, with key roles for W, C, $\mathrm{M}$ and $\mathrm{H}$. The analysis of $r f$ differences between $\mathrm{SC}^{4}$ and $\mathrm{C}^{8}$ reinforces our first observation: different contacts are taken into account and thus different interactions are highlighted with W, F, Y, H, C. At the opposite, contacts with Glycine are underprivileged.

For protein larger than 150 residues, the chain length of the chain does not have an impact. At the opposite, small proteins show strong specificities even if they have classical amino acid distribution. Cysteine and Tryptophan contact numbers are higher. This could 
have some importance for protein modelling approach. At the opposite, amino acids frequencies according to SCOP classes diverge clearly from databank values, but it has few consequences on $r f$ values. Nonetheless, we could notice specialisation according to protein classes.

In the same way, prediction of side-chain positioning also shows strong divergences; SCWRL prediction gives only $55 \%$ of contacts in common with $\mathrm{SC}^{4}$. This result reveals that the percentage of correctly positioned rotamers is not the only way to assess the correctness of a prediction. More precisely, SCWRL brings an over-representation of the disulphide bridges and decreases the interactions between charged residues. This may be due to the importance of the energetic term in the new SCWRL [92]. The interactions with Tryptophan are also badly evaluated: it is clearly related with the poor $\chi^{2}$ rotamer prediction rate of this huge amino acid [92]. For charged residues, the poor prediction is linked to their high accessibilities, i.e. they are difficult to predict and frequently associated to lower electron density [132]. Nonetheless, a step of molecular minimization of the structures with side chains repositioned by SCWRL could be done to know if these errors can be corrected. It could be especially interesting for SCAP which uses a classical forcefield that strongly influence on the results.

The prediction accuracies for $\chi^{1}$ and $\chi^{1+2}$ dihedral angles are $82.6 \%$ and $73.7 \%$, respectively for SCWRL and SCAP, 88.5\% and 79.2\% for SCCOMP, $94 \%$ and $89 \%$ for SCAP and $84.7 \%$ and $71.6 \%$ for IRECS as given in their respective papers. Thus, most sidechain prediction methods yield very good prediction rates. In many ways this is due (i) to the relative similarity of methods and (ii) to rotamer libraries that share also great similarity. The difference we observe shows that a prediction assessment simply based on $\chi^{1}$ and $\chi^{1+2}$ as some limitation and mask significant differences in the predicted structures. Indeed, other angles are very important like for aromatic and aliphatic residues, and these angles are not 
assessed for each method. At the opposite, for side-chain distances, positions of all atoms are important. In the same way, due to the absence of correct representation of the solvent, prediction of exposed residues is difficult to evaluate. The crystal could also constrain exposed residues and so most of prediction accuracy is given only for core residues [94]. This study highlights the interest of using other criteria to evaluate side-chain prediction methods. Moreover, it could have consequence on protein structure modelling.

A simple fact is observed here: methods have recurrent biases that have been highlighted by the computation of $r f$ values. Hence, it will be possible to correct it using this information. In the same way, it could be interesting to combine multiple to create a consensus approach.

For future works, we would like to go deeper in this analysis, but also analyze protein structure dissection done by the Protein Peeling approach. This latter dissects a protein into Protein Units (PUs). A PU is a compact sub-region of the 3D structure. Protein Peeling works from the $\mathrm{C} \alpha$-contact matrix translated into contact probabilities with an optimization procedure $[133,134]$. We will characterize the potential specificities of contacts within PUs (intra-PUs) or at the interface, between PUs (inter-PUs).

\section{Acknowledgments}

The authors want to express their appreciation and wish to acknowledge the contribution of Pr. Catherine Etchebest for her kind help in the course of this research. This work was supported by French Institute for Health and Medical Care (INSERM) and University Paris Diderot - Paris 7. AB benefits from a grant of the Ministère de la Recherche. 


\section{Figure Legends}

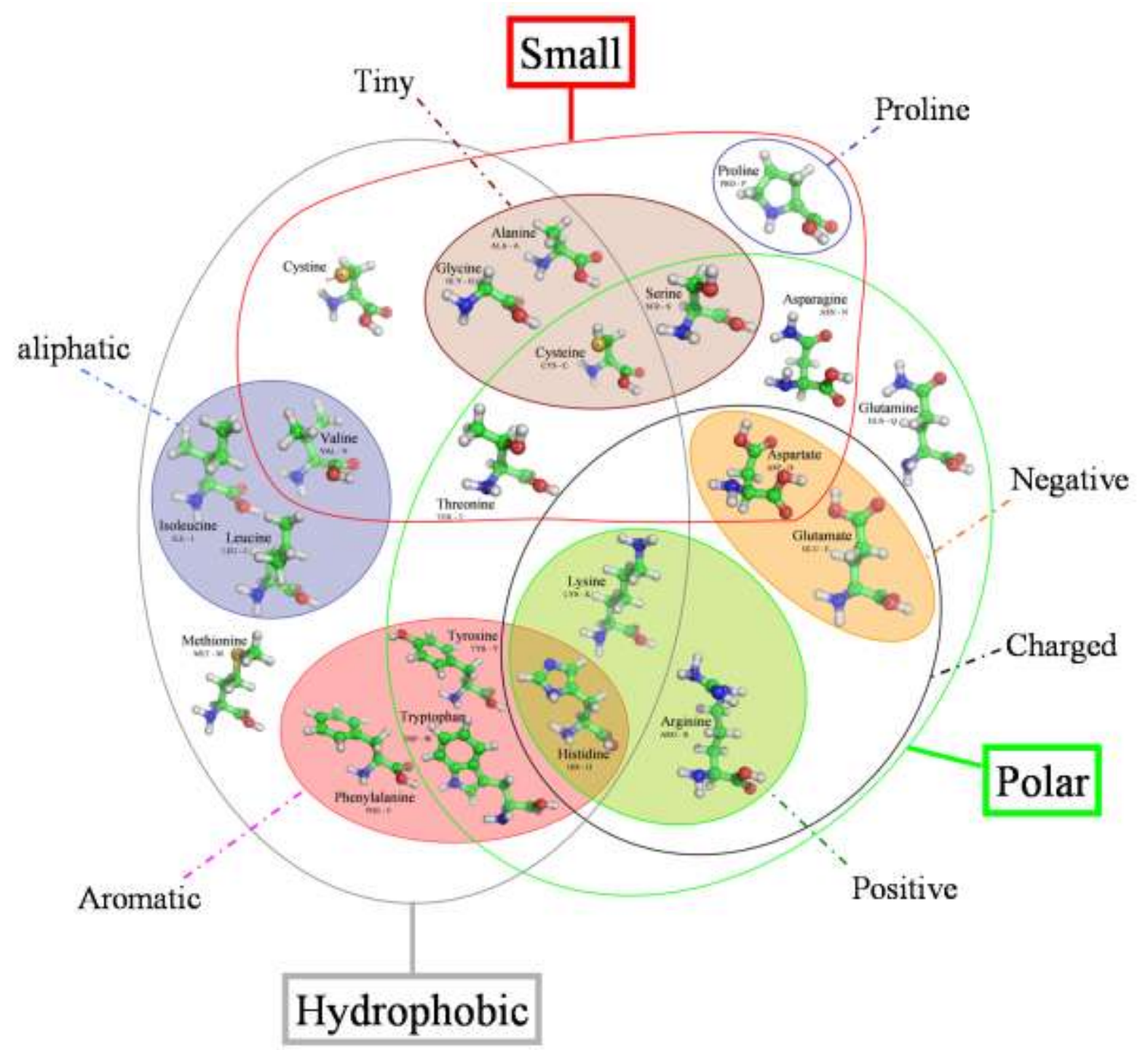

Figure 1. Venn diagram grouping amino acids according to their properties (adapted from $[1,2])$. The representation has been done using PyMol [135]. 


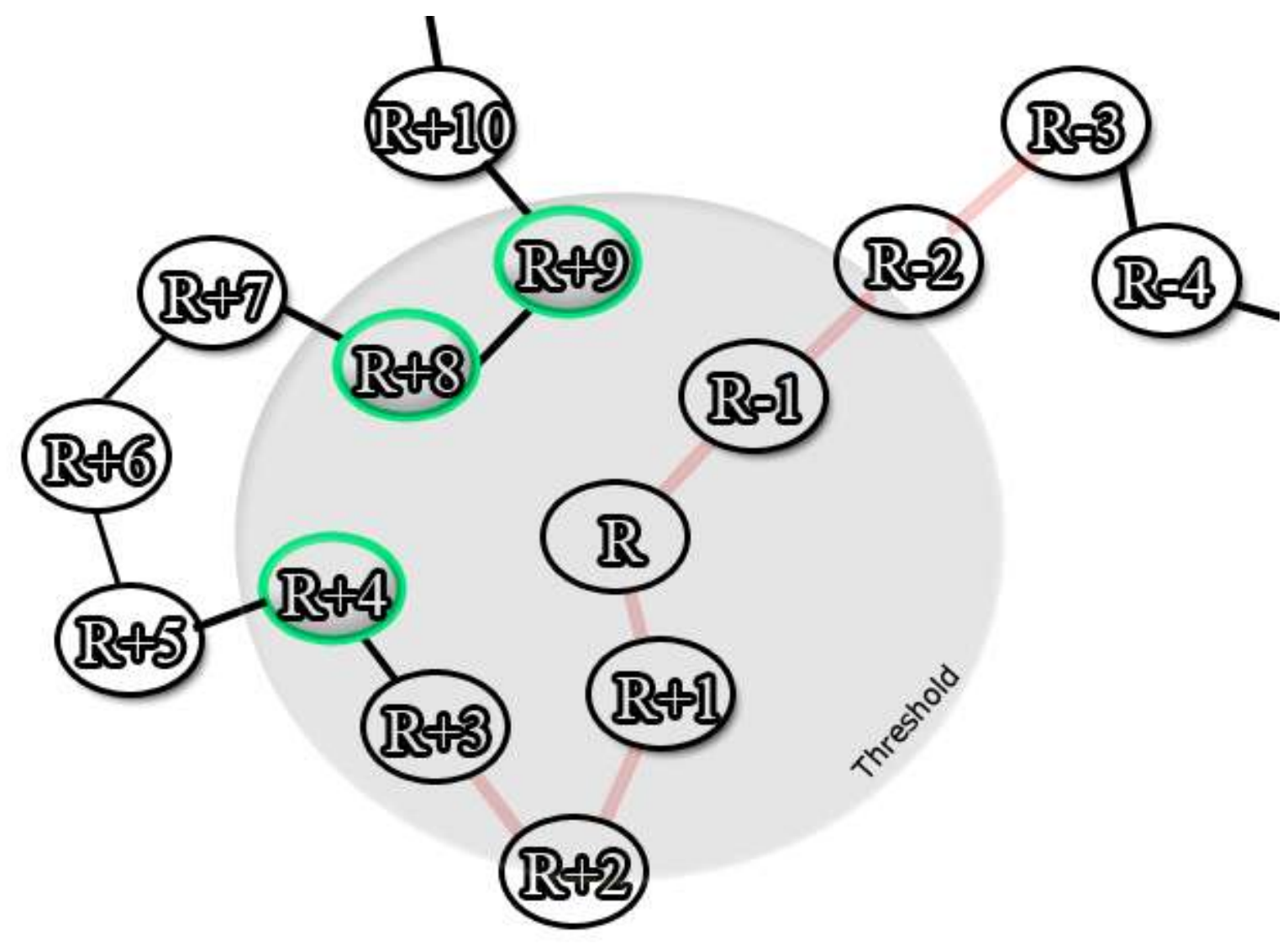

Figure 2. Contact definition. The gray circle represents the distance threshold $\tau$, i.e. the authorized maximum distance. In red the neighboring of the residue $\mathrm{R}$ is indicated (with $D=6$ residues are not taken into account for the analysis). The residues in green are considered in contact with the residue $R$. 


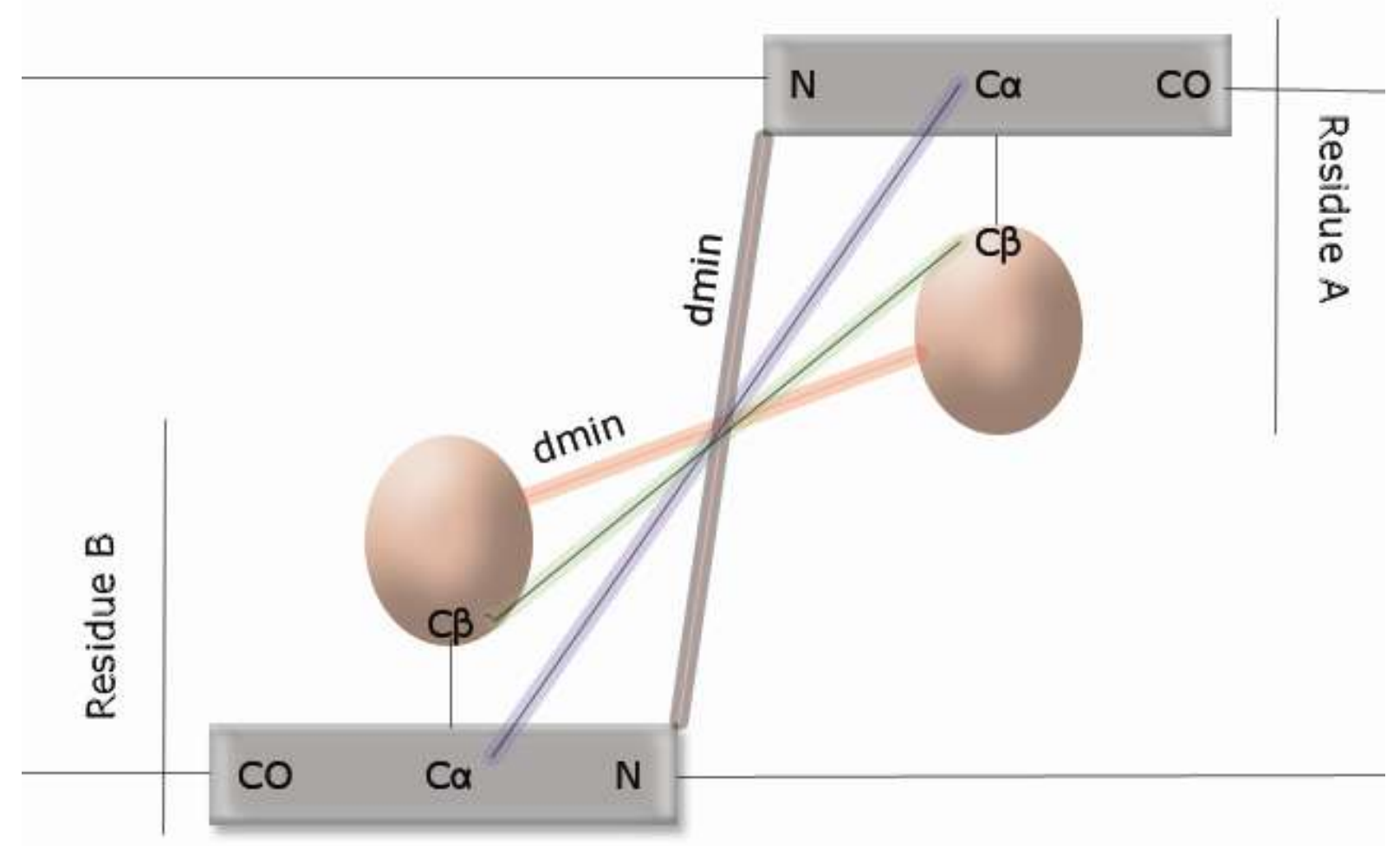

Figure 3. Schematic representation of various distances: (blue) distance $C_{\alpha}-C_{\alpha}$, (green) distance $C_{\beta}-C_{\beta}$ (red) minimal distances between heavy atoms of the side chains of the two residues, (grey) minimal distance between heavy atoms of the protein backbone of the two residues. 


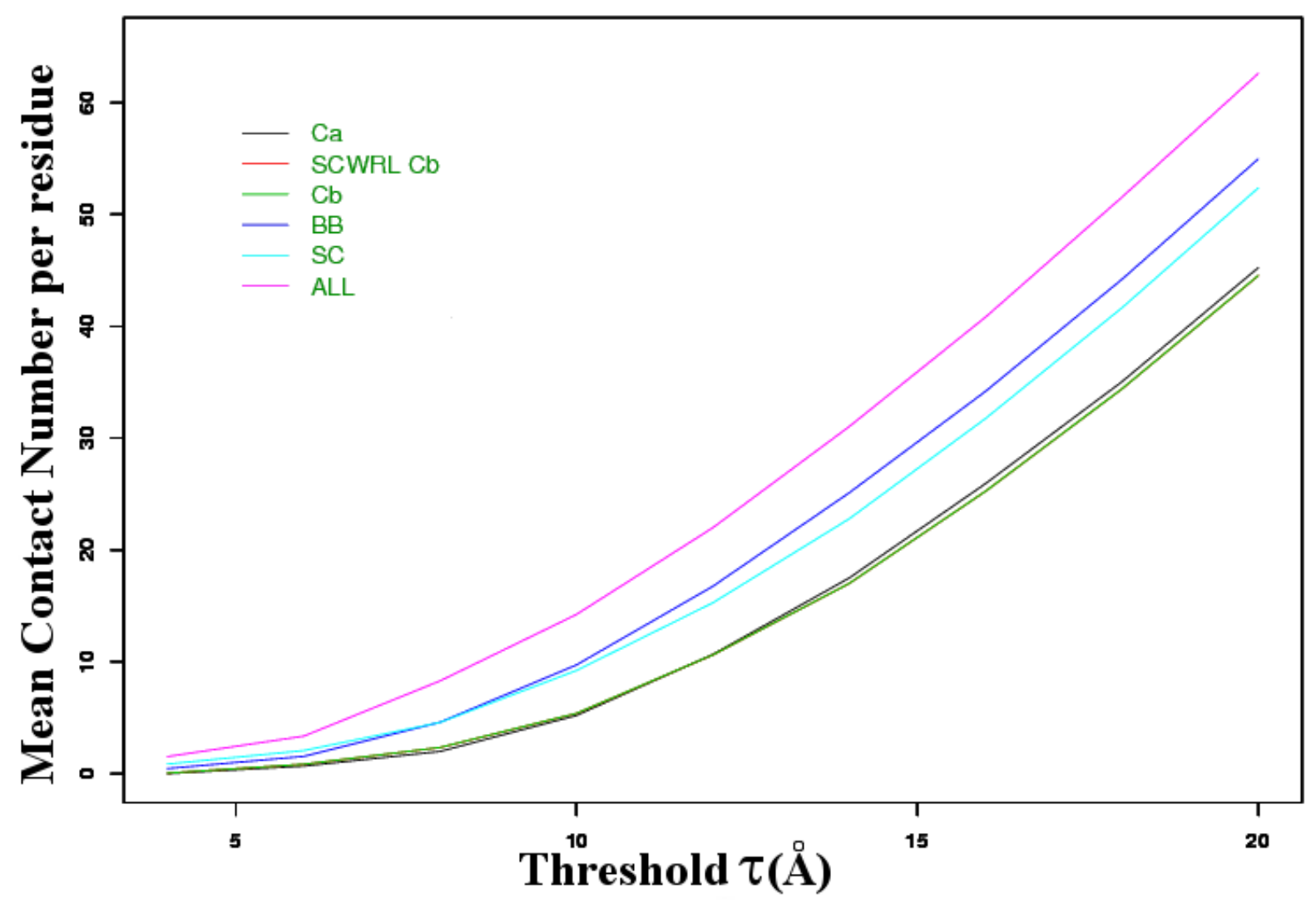

Figure 4. Evolution of the mean contacts number per residue. (x-axis) threshold $\tau$, (y-axis) mean number of contacts. Distances $\mathrm{C} \alpha, \mathrm{C} \beta, \mathrm{BB}, \mathrm{SC}$ and ALL are given; the distance $\mathrm{C} \beta$ with side-chains replaced by SCWRL is also shown. 


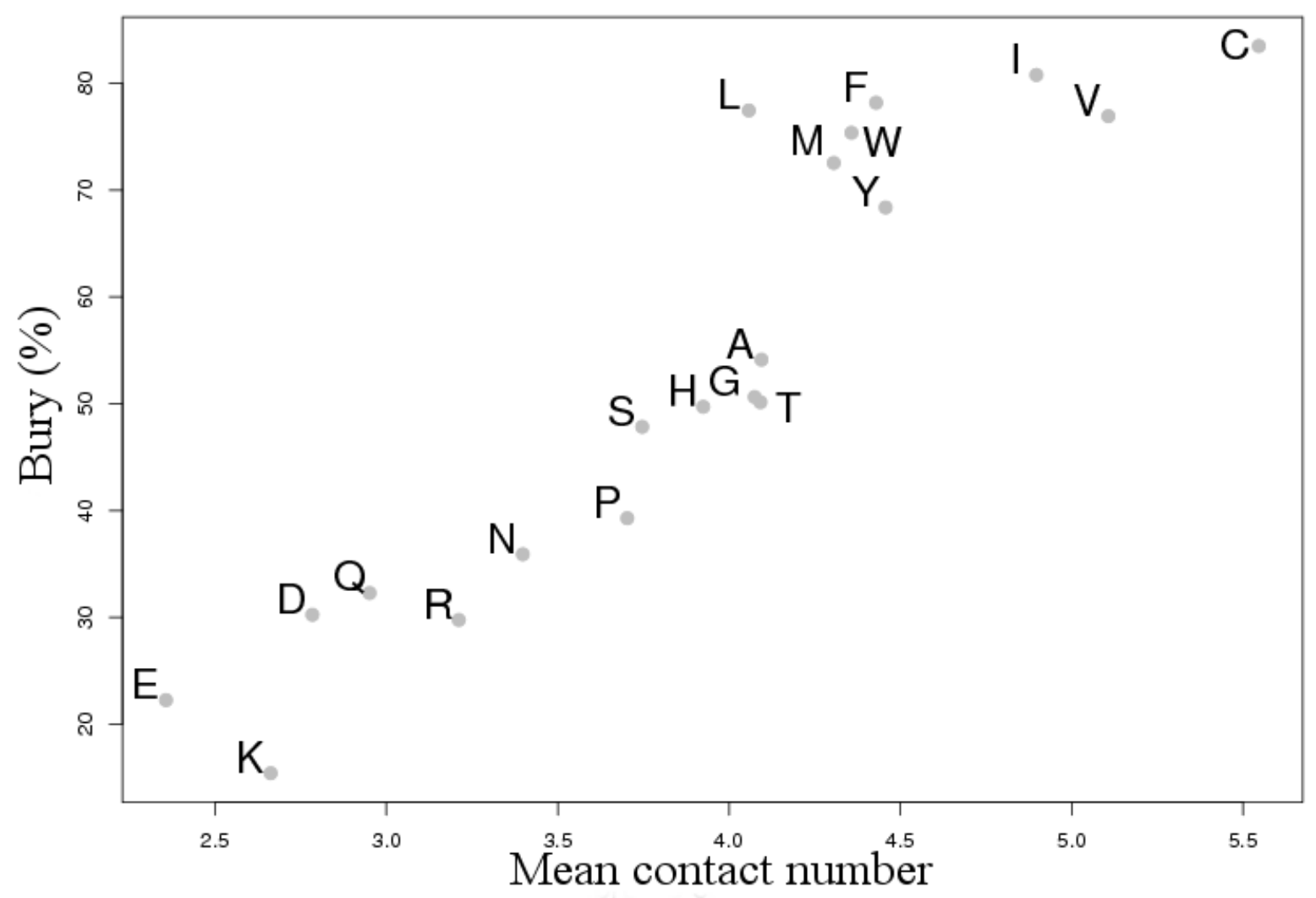

Figure 5. Relative accessibility according to the mean number of contacts for $C \alpha^{8}$.

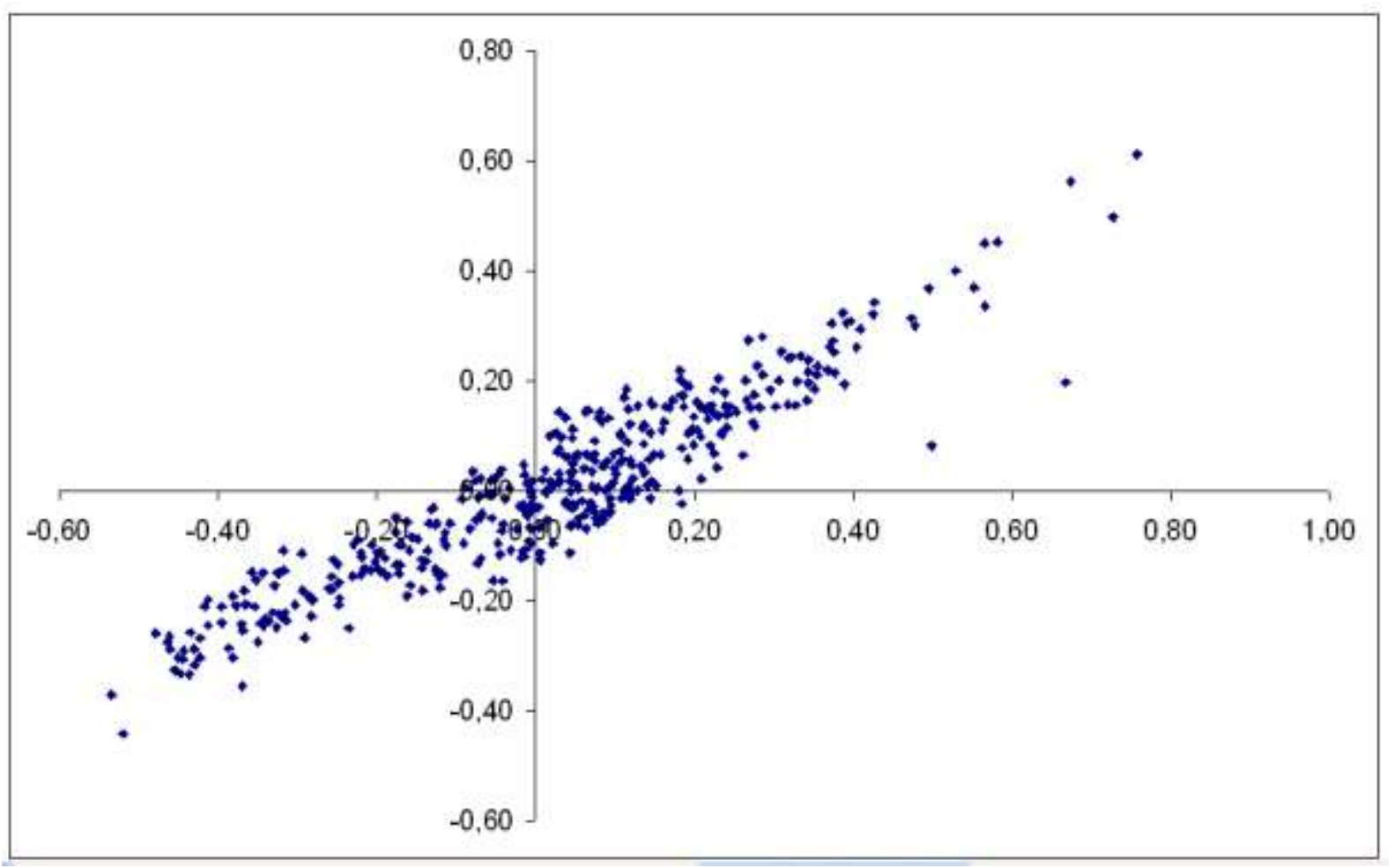

Figure 6. Correlation between (x-axis) the difference between $r f$ for $C \alpha^{8}$ and $C \alpha^{20}$ and (yaxis) $r f$ of $C \alpha^{8}$. 
Table 1. Analysis of contacts according to their proximity in the sequence.

\begin{tabular}{|c|c|c|c|}
\hline aa & $\begin{array}{c}\text { Near contacts } \\
\text { (5 to } 20 \text { residues) }\end{array}$ & $\begin{array}{c}\text { Far contacts } \\
\text { (21 to } 50 \text { residues) }\end{array}$ & $\begin{array}{l}\text { Far contacts } \\
\text { (> } 50 \text { residues) }\end{array}$ \\
\hline C & all & all & not ARNEKV \\
\hline $\mathrm{Y}$ & PFMKLIE & IFY & QKPY \\
\hline $\mathrm{F}$ & Y W L I & MFM Y & C HFW Y L \\
\hline M & M F & M & ACM $F W Y V$ \\
\hline $\mathrm{T}$ & - & D T & $\mathrm{N}$ \\
\hline $\mathrm{H}$ & - & D HSW & $\mathrm{DEH}$ \\
\hline G & - & N D Q G H P S & R N D Q G H P S T \\
\hline $\mathrm{N}$ & - & - & $\mathrm{N}$ \\
\hline S & - & ND & D \\
\hline Q & - & - & - \\
\hline$P$ & - & - & $\mathrm{Q}, \mathrm{E}, \mathrm{W}$ \\
\hline V & 14 & 16 & 9 \\
\hline A & - & $A, L$ & $A, I, L, V$ \\
\hline I & $\mathrm{V}, \mathrm{Y}, \mathrm{F}, \mathrm{M}, \mathrm{K}, \mathrm{L}, \mathrm{I}, \mathrm{A}$ & $\begin{array}{c}A, R, C, E, I, L, K, M, F, \\
T, W, Y, V\end{array}$ & I, L, M, F, Y, V, \\
\hline $\mathrm{L}$ & $V L A$ & $V L A$ & VLAI \\
\hline D & not 18 & not 12 & not 14 \\
\hline $\mathrm{E}$ & not 18 & not 18 & not 18 \\
\hline $\mathrm{R}$ & CIKM & not 12 & not 10 \\
\hline $\mathrm{K}$ & not 15 & not 18 & not 18 \\
\hline
\end{tabular}


Table 2. Analysis of contacts according to the size of the proteins.

\begin{tabular}{|c|c|c|c|c|c|c|}
\hline & & & & prote & length & \\
\hline & amino acids & $C \alpha^{8}$ & $<150$ & 150 to 251 & 251 to 400 & $>400$ \\
\hline inversion & {$[\mathrm{A} \rightarrow \mathrm{M}]$} & 1.12 & $\underline{0.68}$ & 1.04 & 1.07 & 1.21 \\
\hline & {$[\mathrm{M} \rightarrow \mathrm{A}]$} & 1.11 & $\underline{0.69}$ & 1.06 & 1.05 & 1.20 \\
\hline & {$[\mathrm{C} \rightarrow \mathrm{M}]$} & 1.18 & $\underline{0.78}$ & 1.18 & 1.22 & 1.22 \\
\hline & {$[\mathrm{C} \rightarrow \mathrm{H}]$} & 1.09 & $\underline{0.70}$ & 1.10 & 1.17 & 1.05 \\
\hline & {$[\mathrm{F} \rightarrow \mathrm{M}]$} & 1.22 & $\underline{0.86}$ & 1.12 & 1.27 & 1.24 \\
\hline & {$[\mathrm{K} \rightarrow \mathrm{C}]$} & 1.28 & $\underline{0.98}$ & 1.22 & 1.37 & 1.29 \\
\hline & {$[\mathrm{S} \rightarrow \mathrm{W}]$} & 1.12 & $\underline{0.85}$ & 1.20 & 1.08 & 1.14 \\
\hline & {$[\mathrm{T} \rightarrow \mathrm{H}]$} & 1.04 & $\underline{0.80}$ & 1.03 & 1.09 & 1.03 \\
\hline & {$[\mathrm{W} \rightarrow \mathrm{P}]$} & 1.15 & $\underline{0.91}$ & 0.97 & 1.11 & 1.27 \\
\hline & {$[\mathrm{N} \rightarrow \mathrm{H}]$} & 1.08 & $\underline{0.85}$ & 1.09 & 1.14 & 1.03 \\
\hline & {$[E \rightarrow S]$} & 1.05 & $\underline{0.84}$ & 1.00 & 1.04 & 1.10 \\
\hline & {$[\mathrm{S} \rightarrow \mathrm{M}]$} & 1.05 & $\underline{0.85}$ & 0.96 & 1.05 & 1.08 \\
\hline change: & {$[\mathrm{M} \rightarrow \mathrm{C}]$} & 1.55 & 1.17 & 1.68 & 1.62 & 1.55 \\
\hline & {$[\mathrm{H} \rightarrow \mathrm{C}]$} & 1.57 & 1.19 & 1.70 & 1.69 & 1.45 \\
\hline & {$[\mathrm{H} \rightarrow \mathrm{H}]$} & 1.35 & 1.02 & 1.31 & 1.33 & 1.43 \\
\hline & {$[\mathrm{W} \rightarrow \mathrm{S}]$} & 0.98 & 0.67 & 0.97 & 0.96 & 1.04 \\
\hline & {$[\mathrm{Y} \rightarrow \mathrm{C}]$} & 1.41 & 1.11 & 1.51 & 1.44 & 1.41 \\
\hline & {$[Q \rightarrow Q]$} & 0.86 & 0.56 & 0.92 & 0.80 & 0.92 \\
\hline & {$[\mathrm{C} \rightarrow \mathrm{A}]$} & 0.99 & 0.71 & 0.87 & 1.07 & 1.03 \\
\hline & {$[A \rightarrow C]$} & 1.32 & 1.06 & 1.22 & 1.44 & 1.32 \\
\hline & {$[\mathrm{F} \rightarrow \mathrm{C}]$} & 1.50 & 1.25 & 1.35 & 1.61 & 1.52 \\
\hline & {$[\mathrm{D} \rightarrow \mathrm{H}]$} & 1.28 & 1.05 & 1.14 & 1.39 & 1.25 \\
\hline & {$[\mathrm{K} \rightarrow \mathrm{H}]$} & 0.86 & 0.64 & 0.85 & 0.86 & 0.90 \\
\hline & {$[\mathrm{M} \rightarrow \mathrm{F}]$} & 1.27 & 1.06 & 1.24 & 1.29 & 1.28 \\
\hline & {$[\mathrm{N} \rightarrow \mathrm{N}]$} & 1.39 & 1.52 & 1.26 & 1.61 & 1.21 \\
\hline & {$[\mathrm{V} \rightarrow \mathrm{F}]$} & 1.19 & 1.40 & 1.23 & 1.19 & 1.15 \\
\hline & {$[S \rightarrow C]$} & 1.48 & 1.69 & 1.60 & 1.48 & 1.41 \\
\hline & {$[\mathrm{M} \rightarrow \mathrm{L}]$} & 1.09 & 1.30 & 1.13 & 1.07 & 1.08 \\
\hline & {$[\mathrm{R} \rightarrow \mathrm{W}]$} & 1.27 & 1.48 & 1.32 & 1.24 & 1.23 \\
\hline & {$[\mathrm{M} \rightarrow \mathrm{V}]$} & 1.39 & 1.61 & 1.49 & 1.49 & 1.26 \\
\hline & {$[\mathrm{Q} \rightarrow \mathrm{W}]$} & 1.30 & 1.52 & 1.45 & 1.27 & 1.25 \\
\hline & {$[\mathrm{H} \rightarrow \mathrm{V}]$} & 1.20 & 1.42 & 1.29 & 1.18 & 1.15 \\
\hline & {$[\mathrm{Y} \rightarrow \mathrm{I}]$} & 1.37 & 1.59 & 1.42 & 1.42 & 1.28 \\
\hline & {$[\mathrm{K} \rightarrow \mathrm{F}]$} & 1.09 & 1.31 & 1.13 & 1.06 & 1.06 \\
\hline & {$[\mathrm{Y} \rightarrow \mathrm{F}]$} & 1.28 & 1.51 & 1.28 & 1.27 & 1.26 \\
\hline & {$[\mathrm{S} \rightarrow \mathrm{Y}]$} & 1.07 & 1.32 & 1.14 & 1.02 & 1.06 \\
\hline & {$[\mathrm{T} \rightarrow \mathrm{I}]$} & 1.24 & 1.49 & 1.22 & 1.27 & 1.20 \\
\hline & {$[\mathrm{H} \rightarrow \mathrm{Y}]$} & 1.11 & 1.38 & 1.22 & 1.05 & 1.10 \\
\hline & {$[\mathrm{Y} \rightarrow \mathrm{Y}]$} & 1.39 & 1.67 & 1.40 & 1.33 & 1.40 \\
\hline & {$[\mathrm{F} \rightarrow \mathrm{Y}]$} & 1.28 & 1.56 & 1.29 & 1.26 & 1.26 \\
\hline & {$[\mathrm{W} \rightarrow \mathrm{M}]$} & 1.23 & 1.52 & 1.09 & 1.28 & 1.19 \\
\hline & {$[\mathrm{F} \rightarrow \mathrm{W}]$} & 1.27 & 1.57 & 1.42 & 1.26 & 1.18 \\
\hline & {$[\mathrm{Q} \rightarrow \mathrm{C}]$} & 1.38 & 1.70 & 1.60 & 1.27 & 1.33 \\
\hline & {$[\mathrm{W} \rightarrow \mathrm{F}]$} & 1.32 & 1.66 & 1.46 & 1.31 & 1.23 \\
\hline & {$[\mathrm{M} \rightarrow \mathrm{M}]$} & 1.67 & 2.01 & 1.54 & 1.74 & 1.55 \\
\hline & {$[\mathrm{H} \rightarrow \mathrm{F}]$} & 1.15 & 1.49 & 1.30 & 1.09 & 1.11 \\
\hline & {$[\mathrm{W} \rightarrow \mathrm{W}]$} & 1.50 & 1.85 & 1.34 & 1.51 & 1.52 \\
\hline & {$[\mathrm{D} \rightarrow \mathrm{C}]$} & 1.33 & 1.70 & 1.50 & 1.35 & 1.20 \\
\hline & {$[\mathrm{K} \rightarrow \mathrm{W}]$} & 1.04 & 1.42 & 1.08 & 1.03 & 1.00 \\
\hline
\end{tabular}




\begin{tabular}{|l|l|l|l|l|l|}
{$[\mathrm{C} \rightarrow \mathrm{W}]$} & 1.13 & $\mathbf{1 . 5 9}$ & 1.15 & 1.22 & 0.95 \\
{$[\mathrm{M} \rightarrow \mathrm{W}]$} & 1.23 & $\mathbf{1 . 7 7}$ & 1.18 & 1.25 & 1.19 \\
{$[\mathrm{~W} \rightarrow \mathrm{C}]$} & 1.47 & $\mathbf{2 . 0 5}$ & 1.52 & 1.65 & $\mathbf{1 . 2 1}$ \\
{$[\mathrm{C} \rightarrow \mathrm{C}]$} & 6.14 & $\mathbf{9 . 5 1}$ & $\mathbf{6 . 8 8}$ & $\mathbf{4 . 9 7}$ & $\mathbf{5 . 4 7}$ \\
\hline
\end{tabular}

G. P. I. L nothing special

bold : difference $>0.2$; italics : $<0.1$. underline : change

Table 3. Analysis of protein contacts within SCOP classes.

\begin{tabular}{|c|c|c|c|c|c|c|}
\hline \multirow{3}{*}{ inversion } & & \multirow{2}{*}{$\frac{\mathrm{C} \alpha^{8}}{1.21}$} & \multirow{2}{*}{$\frac{\text { all- } \alpha}{1.77}$} & \multirow{2}{*}{$\frac{\text { all- } \beta}{1.02}$} & \multirow{2}{*}{$\frac{\alpha / \beta}{0.95}$} & \multirow{2}{*}{$\frac{\alpha+\beta}{1.22}$} \\
\hline & {$[\mathrm{H} \rightarrow \mathrm{W}]$} & & & & & \\
\hline & {$[\mathrm{W} \rightarrow \mathrm{W}]$} & 1.50 & 1.80 & 1.60 & $\overline{1.54}$ & 0.98 \\
\hline & {$[\mathrm{W} \rightarrow \mathrm{H}]$} & 1.09 & 1.47 & $\underline{0.94}$ & $\underline{0.92}$ & $\overline{1.17}$ \\
\hline & {$[\mathrm{N} \rightarrow \mathrm{N}]$} & 1.39 & 1.21 & $\overline{1.34}$ & $\overline{1.51}$ & $\underline{0.93}$ \\
\hline & {$[\mathrm{C} \rightarrow \mathrm{W}]$} & 1.13 & 0.99 & 1.17 & $\underline{0.89}$ & 1.37 \\
\hline & {$[\mathrm{C} \rightarrow \mathrm{M}]$} & 1.18 & 0.95 & 1.34 & 1.17 & $\underline{0.94}$ \\
\hline & {$[\mathrm{W} \rightarrow \mathrm{Q}]$} & 0.89 & 0.80 & 0.87 & 0.83 & $\underline{1.16}$ \\
\hline & {$[\mathrm{H} \rightarrow \mathrm{P}]$} & 1.03 & 1.24 & $\underline{0.90}$ & 1.05 & 0.89 \\
\hline & {$[\mathrm{C} \rightarrow \mathrm{H}]$} & 1.09 & $\underline{0.81}$ & 1.19 & 1.08 & 1.09 \\
\hline & {$[\mathrm{M} \rightarrow \mathrm{W}]$} & 1.23 & $\overline{1.27}$ & 1.26 & 1.08 & $\underline{0.96}$ \\
\hline & {$[\mathrm{M} \rightarrow \mathrm{P}]$} & 0.93 & $\underline{1.05}$ & 0.86 & 0.99 & 0.72 \\
\hline & {$[\mathrm{K} \rightarrow \mathrm{P}]$} & 0.92 & $\underline{1.14}$ & 0.79 & 0.93 & 0.96 \\
\hline & {$[R \rightarrow P]$} & 1.03 & 1.24 & $\underline{0.93}$ & $\underline{0.99}$ & $\underline{0.96}$ \\
\hline & {$[\mathrm{H} \rightarrow \mathrm{M}]$} & 1.14 & $\underline{0.92}$ & 1.20 & 1.22 & 1.08 \\
\hline & {$[\mathrm{N} \rightarrow \mathrm{W}]$} & 1.08 & $\underline{0.87}$ & 1.04 & 1.15 & 1.17 \\
\hline & {$[\mathrm{M} \rightarrow \mathrm{H}]$} & 1.04 & $\underline{0.83}$ & 1.12 & 1.11 & 1.01 \\
\hline & {$[\mathrm{P} \rightarrow \mathrm{M}]$} & 1.07 & 1.08 & 1.05 & 1.12 & $\underline{0.86}$ \\
\hline & {$[\mathrm{W} \rightarrow \mathrm{M}]$} & 1.23 & 1.16 & 1.24 & 1.15 & $\underline{0.98}$ \\
\hline change: & {$[\mathrm{M} \rightarrow \mathrm{M}]$} & 1.67 & 1.73 & 1.88 & 1.68 & 1.67 \\
\hline & {$[\mathrm{E} \rightarrow \mathrm{C}]$} & 1.29 & 1.05 & 1.31 & 1.24 & 1.17 \\
\hline & {$[\mathrm{G} \rightarrow \mathrm{H}]$} & 1.10 & 1.00 & 1.14 & 1.12 & 1.30 \\
\hline & {$[C \rightarrow R]$} & 0.70 & 0.74 & 0.91 & 0.58 & 0.73 \\
\hline & {$[\mathrm{C} \rightarrow \mathrm{F}]$} & 1.18 & 1.44 & 1.15 & 1.16 & 1.14 \\
\hline & {$[\mathrm{W} \rightarrow \mathrm{N}]$} & 0.86 & 0.62 & 0.85 & 0.96 & 0.88 \\
\hline & {$[\mathrm{P} \rightarrow \mathrm{C}]$} & 1.40 & 1.11 & 1.22 & 1.46 & 1.30 \\
\hline & {$[\mathrm{W} \rightarrow \mathrm{P}]$} & 1.15 & 1.41 & 1.09 & 1.17 & 1.08 \\
\hline & {$[\mathrm{P} \rightarrow \mathrm{W}]$} & 1.33 & 1.59 & 1.36 & 1.25 & 1.26 \\
\hline & {$[\mathrm{D} \rightarrow \mathrm{H}]$} & 1.28 & 1.20 & 1.41 & 1.25 & 1.55 \\
\hline & {$[A \rightarrow C]$} & 1.32 & 1.41 & 1.10 & 1.39 & 1.49 \\
\hline & {$[\mathrm{T} \rightarrow \mathrm{C}]$} & 1.34 & 1.06 & 1.23 & 1.47 & 1.41 \\
\hline & {$[\mathrm{H} \rightarrow \mathrm{H}]$} & 1.35 & 1.26 & 1.43 & 1.31 & 1.70 \\
\hline & {$[\mathrm{M} \rightarrow \mathrm{C}]$} & 1.55 & 1.18 & 1.68 & 1.56 & 1.28 \\
\hline & {$[\mathrm{H} \rightarrow \mathrm{C}]$} & 1.57 & 1.11 & 1.59 & 1.58 & 1.57 \\
\hline & {$[\mathrm{Q} \rightarrow \mathrm{W}]$} & 1.30 & 1.30 & 1.17 & 1.20 & 1.69 \\
\hline & {$[\mathrm{W} \rightarrow \mathrm{C}]$} & 1.47 & 1.13 & 1.45 & 1.25 & 1.90 \\
\hline & {$[\mathrm{C} \rightarrow \mathrm{C}]$} & 6.14 & 7.91 & 7.18 & 4.55 & 5.73 \\
\hline
\end{tabular}

I. L. F. S. Y. V nothing special

bold : difference $>0.2$; italics : $<0.1$. underline : change 
Table 4. Analysis of contacts predicted by side-chain conformation prediction methods (for $\left.S C^{4}\right)$.

\begin{tabular}{|c|c|c|c|c|c|c|c|c|}
\hline & $\begin{array}{c}\text { Protein } \\
(\%)\end{array}$ & $\begin{array}{c}\text { Contact } \\
\text { numbers } \\
(\%)\end{array}$ & $\begin{array}{c}\text { DB } \\
(\%)\end{array}$ & $\begin{array}{c}\text { SCWRL } \\
(\%)\end{array}$ & $\begin{array}{c}\text { SCATD } \\
(\%)\end{array}$ & $\begin{array}{c}\text { IRECS } \\
(\%)\end{array}$ & $\begin{array}{c}\text { SCAP } \\
(\%)\end{array}$ & $\begin{array}{c}\text { SCCOMP } \\
(\%)\end{array}$ \\
\hline DB & 100.0 & -- & -- & 60.5 & 54.8 & 64.0 & 59.6 & 61.2 \\
\hline SCWRL & 100.0 & -12.2 & 68.9 & -- & 62.0 & 75.7 & 64.4 & 71.5 \\
\hline SCATD & 100.0 & -5.8 & 64.5 & 64.1 & -- & 68.3 & 61.1 & 71.1 \\
\hline IRECS & 100.0 & -15.0 & 68.0 & 70.6 & 61.7 & -- & 61.4 & 67.9 \\
\hline SCAP & 99.4 & +53.1 & 36.9 & 36.7 & 33.9 & 37.5 & -- & 35.5 \\
\hline SCCOMP & 98.9 & -1.4 & 61.2 & 62.8 & 60.4 & 64.0 & 55.1 & -- \\
\hline
\end{tabular}

Table 5. Difference of rf values between side-chain prediction conformation methods (values $x 10^{-2}$ ).

\begin{tabular}{|c|c|c|c|c|c|c|}
\hline & DB & SCWRL & SCATD & IRECS & SCAP & SCCOMP \\
\hline DB & -- & 7.4 & 9.6 & 5.7 & 24.4 & 6.2 \\
\hline SCWRL & -- & -- & 4.0 & 5.1 & 22.0 & 4.6 \\
\hline SCATD & -- & -- & -- & 6.6 & 21.0 & 5.6 \\
\hline IRECS & -- & -- & -- & -- & 23.0 & 4.9 \\
\hline SCAP & -- & -- & -- & -- & -- & 22.0 \\
\hline SCCOMP & -- & -- & -- & -- & -- & -- \\
\hline
\end{tabular}


Table 6. Analysis of amino acid contact with side-chain prediction conformation method SCWRL.

\begin{tabular}{|l|r|r|}
\cline { 2 - 3 } \multicolumn{1}{c|}{} & $\mathrm{SC}^{4}$ & $\mathrm{SC}^{4}{ }_{\text {scwrl }}$ \\
\hline$[\mathrm{C}->\mathrm{C}]$ & 12.96 & 14.19 \\
{$[\mathrm{D}->\mathrm{R}]$} & 3.16 & 2.58 \\
{$[\mathrm{E}->\mathrm{R}]$} & 3.17 & 2.55 \\
\hline$[\mathrm{G}->\mathrm{W}]$ & 2.52 & 2.31 \\
{$[\mathrm{~W}->\mathrm{F}]$} & 2.19 & 1.98 \\
{$[\mathrm{P}->\mathrm{R}]$} & 1.28 & 1.07 \\
{$[\mathrm{R}->\mathrm{D}]$} & 1.98 & 1.76 \\
{$[\mathrm{P}->\mathrm{Y}]$} & 3.03 & 2.79 \\
{$[\mathrm{D}->\mathrm{K}]$} & 1.90 & 1.66 \\
{$[\mathrm{M}->\mathrm{F}]$} & 2.50 & 2.25 \\
{$[\mathrm{~T}->\mathrm{W}]$} & 2.03 & 1.77 \\
{$[\mathrm{G}->\mathrm{R}]$} & 1.28 & 1.02 \\
{$[\mathrm{P}->\mathrm{W}]$} & 3.68 & 3.42 \\
{$[\mathrm{E}->\mathrm{K}]$} & 1.93 & 1.66 \\
{$[\mathrm{R}->\mathrm{E}]$} & 1.98 & 1.68 \\
{$[\mathrm{~K}->\mathrm{D}]$} & 2.25 & 1.94 \\
{$[\mathrm{~S}->\mathrm{W}]$} & 2.25 & 1.92 \\
{$[\mathrm{Y}->\mathrm{W}]$} & 2.21 & 1.88 \\
{$[\mathrm{~W}->\mathrm{W}]$} & 2.88 & 2.54 \\
{$[\mathrm{l}->\mathrm{W}]$} & 2.17 & 1.83 \\
{$[\mathrm{~K}->\mathrm{E}]$} & 2.27 & 1.88 \\
{$[\mathrm{~A}->\mathrm{W}]$} & 2.47 & 2.05 \\
{$[\mathrm{~V}->\mathrm{W}]$} & 2.14 & 1.72 \\
{$[\mathrm{~L}->\mathrm{W}]$} & 2.44 & 2.01 \\
{$[\mathrm{~F}->\mathrm{W}]$} & 2.58 & 2.15 \\
{$[\mathrm{M}->\mathrm{W}]$} & 2.80 & 2.31 \\
\hline
\end{tabular}




\section{Reference}

[1] Taylor W.R., The classification of amino acid conservation, J Theor Biol 119 (1986) 205-218.

[2] Livingstone C.D., Barton G.J., Protein sequence alignments: a strategy for the hierarchical analysis of residue conservation, Comput Appl Biosci 9 (1993) 745-756.

[3] Rost B., Review: protein secondary structure prediction continues to rise, J Struct Biol 134 (2001) 204218.

[4] Jones D.T., Protein secondary structure prediction based on position-specific scoring matrices, J Mol Biol 292 (1999) 195-202.

[5] Pollastri G., McLysaght A., Porter: a new, accurate server for protein secondary structure prediction, Bioinformatics 21 (2005) 1719-1720.

[6] Moult J., Fidelis K., Zemla A., Hubbard T., Critical assessment of methods of protein structure prediction (CASP)-round V, Proteins 53 Suppl 6 (2003) 334-339.

[7] Fiser A., Dosztanyi Z., Simon I., The role of long-range interactions in defining the secondary structure of proteins is overestimated, Comput Appl Biosci 13 (1997) 297-301.

[8] Offmann B., Tyagi M., de Brevern A.G., Local Protein Structures, Current Bioinformatics 2 (2007) $165-202$.

[9] de Brevern A.G., Etchebest C., Hazout S., Bayesian probabilistic approach for predicting backbone structures in terms of protein blocks, Proteins 41 (2000) 271-287.

[10] de Brevern A.G., Hazout S., 'Hybrid protein model' for optimally defining 3D protein structure fragments, Bioinformatics 19 (2003) 345-353.

[11] Schuchhardt J., Schneider G., Reichelt J., Schomburg D., Wrede P., Local structural motifs of protein backbones are classified by self-organizing neural networks, Protein Eng 9 (1996) 833-842.

[12] Unger R., Harel D., Wherland S., Sussman J.L., A 3D building blocks approach to analyzing and predicting structure of proteins, Proteins 5 (1989) 355-373.

[13] Sander O., Sommer I., Lengauer T., Local protein structure prediction using discriminative models, BMC Bioinformatics 7 (2006) 14.

[14] de Brevern A.G., Etchebest C., Benros C., Hazout S., "Pinning strategy": a novel approach for predicting the backbone structure in terms of protein blocks from sequence, J Biosci 32 (2007) 51-70.

[15] Etchebest C., Benros C., Hazout S., de Brevern A.G., A structural alphabet for local protein structures: improved prediction methods, Proteins 59 (2005) 810-827.

[16] Tyagi M., Gowri V.S., Srinivasan N., de Brevern A.G., Offmann B., A substitution matrix for structural alphabet based on structural alignment of homologous proteins and its applications, Proteins 65 (2006) 32-39.

[17] Tyagi M., Sharma P., Swamy C.S., Cadet F., Srinivasan N., de Brevern A.G., Offmann B., Protein Block Expert (PBE): a web-based protein structure analysis server using a structural alphabet, Nucleic Acids Res 34 (2006) W119-123.

[18] Tyagi M., de Brevern A.G., Srinivasan N., Offmann B., Protein structure mining using a structural alphabet, Proteins (2008) in press.

[19] Dudev M., Lim C., Discovering structural motifs using a structural alphabet: application to magnesiumbinding sites, BMC Bioinformatics 8 (2007) 106.

[20] Hvidsten T.R., Kryshtafovych A., Komorowski J., Fidelis K., A novel approach to fold recognition using sequence-derived properties from sets of structurally similar local fragments of proteins, Bioinformatics 19 Suppl 2 (2003) ii81-91.

[21] Baker E.N., Hubbard R.E., Hydrogen bonding in globular proteins, Prog Biophys Mol Biol 44 (1984) 97-179.

[22] Burley S.K., Petsko G.A., Weakly polar interactions in proteins, Adv Protein Chem 39 (1988) 125-189. 
[23] Brandl M., Weiss M.S., Jabs A., Suhnel J., Hilgenfeld R., C-H.pi-interactions in proteins, J Mol Biol 307 (2001) 357-377.

[24] Weiss M.S., Brandl M., Suhnel J., Pal D., Hilgenfeld R., More hydrogen bonds for the (structural) biologist, Trends Biochem Sci 26 (2001) 521-523.

[25] Mitchell J.B., Thornton J.M., Singh J., Price S.L., Towards an understanding of the arginine-aspartate interaction, J Mol Biol 226 (1992) 251-262.

[26] Stickle D.F., Presta L.G., Dill K.A., Rose G.D., Hydrogen bonding in globular proteins, J Mol Biol 226 (1992) 1143-1159.

[27] Rose G.D., Wolfenden R., Hydrogen bonding, hydrophobicity, packing, and protein folding, Annu Rev Biophys Biomol Struct 22 (1993) 381-415.

[28] Gromiha M.M., Selvaraj S., Importance of long-range interactions in protein folding, Biophys Chem 77 (1999) 49-68.

[29] Bahar I., Kaplan M., Jernigan R.L., Short-range conformational energies, secondary structure propensities, and recognition of correct sequence-structure matches, Proteins 29 (1997) 292-308.

[30] Russell R.B., Saqi M.A., Bates P.A., Sayle R.A., Sternberg M.J., Recognition of analogous and homologous protein folds--assessment of prediction success and associated alignment accuracy using empirical substitution matrices, Protein Eng 11 (1998) 1-9.

[31] Drablos F., Clustering of non-polar contacts in proteins, Bioinformatics 15 (1999) 501-509.

[32] Gromiha M.M., Thangakani A.M., Selvaraj S., FOLD-RATE: prediction of protein folding rates from amino acid sequence, Nucleic Acids Res 34 (2006) W70-74.

[33] Capriotti E., Casadio R., K-Fold: a tool for the prediction of the protein folding kinetic order and rate, Bioinformatics 23 (2007) 385-386.

[34] Punta M., Rost B., Protein folding rates estimated from contact predictions, J Mol Biol 348 (2005) 507 512.

[35] Zhang L., Skolnick J., How do potentials derived from structural databases relate to "true" potentials? Protein Sci 7 (1998) 112-122.

[36] Miyazawa S., Jernigan R.L., Residue-residue potentials with a favorable contact pair term and an unfavorable high packing density term, for simulation and threading, J Mol Biol 256 (1996) 623-644.

[37] Heringa J., Argos P., Side-chain clusters in protein structures and their role in protein folding, J Mol Biol 220 (1991) 151-171.

[38] Dosztanyi Z., Fiser A., Simon I., Stabilization centers in proteins: identification, characterization and predictions, J Mol Biol 272 (1997) 597-612.

[39] Kannan N., Selvaraj S., Gromiha M.M., Vishveshwara S., Clusters in alpha/beta barrel proteins: implications for protein structure, function, and folding: a graph theoretical approach, Proteins 43 (2001) 103112.

[40] Dedmon M.M., Lindorff-Larsen K., Christodoulou J., Vendruscolo M., Dobson C.M., Mapping longrange interactions in alpha-synuclein using spin-label NMR and ensemble molecular dynamics simulations, J Am Chem Soc 127 (2005) 476-477.

[41] Gugolya Z., Dosztanyi Z., Simon I., Interresidue interactions in protein classes, Proteins 27 (1997) 360366.

[42] Baker D., A surprising simplicity to protein folding, Nature 405 (2000) 39-42.

[43] Pandit A.D., Jha A., Freed K.F., Sosnick T.R., Small proteins fold through transition states with nativelike topologies, J Mol Biol 361 (2006) 755-770.

[44] Paci E., Lindorff-Larsen K., Dobson C.M., Karplus M., Vendruscolo M., Transition state contact orders correlate with protein folding rates, J Mol Biol 352 (2005) 495-500.

[45] Plaxco K.W., Simons K.T., Baker D., Contact order, transition state placement and the refolding rates of single domain proteins, J Mol Biol 277 (1998) 985-994.

[46] Grana O., Baker D., MacCallum R.M., Meiler J., Punta M., Rost B., Tress M.L., Valencia A., CASP6 
assessment of contact prediction, Proteins 61 Suppl 7 (2005) 214-224.

[47] Olmea O., Valencia A., Improving contact predictions by the combination of correlated mutations and other sources of sequence information, Fold Des 2 (1997) S25-32.

[48] Hamilton N., Burrage K., Ragan M.A., Huber T., Protein contact prediction using patterns of correlation, Proteins 56 (2004) 679-684.

[49] Fariselli P., Olmea O., Valencia A., Casadio R., Progress in predicting inter-residue contacts of proteins with neural networks and correlated mutations, Proteins Suppl 5 (2001) 157-162.

[50] Fariselli P., Olmea O., Valencia A., Casadio R., Prediction of contact maps with neural networks and correlated mutations, Protein Eng 14 (2001) 835-843.

[51] Lund O., Frimand K., Gorodkin J., Bohr H., Bohr J., Hansen J., Brunak S., Protein distance constraints predicted by neural networks and probability density functions, Protein Eng 10 (1997) 1241-1248.

[52] Pollastri G., Baldi P., Fariselli P., Casadio R., Improved prediction of the number of residue contacts in proteins by recurrent neural networks, Bioinformatics 17 Suppl 1 (2001) S234-242.

[53] Pollastri G., Baldi P., Prediction of contact maps by GIOHMMs and recurrent neural networks using lateral propagation from all four cardinal corners, Bioinformatics 18 Suppl 1 (2002) S62-70.

[54] Punta M., Rost B., PROFcon: novel prediction of long-range contacts, Bioinformatics 21 (2005) 29602968.

[55] Taylor W.R., Evolutionary transitions in protein fold space, Curr Opin Struct Biol 17 (2007) 354-361.

[56] Joshi R.R., A Decade of Computing to Traverse the Labyrinth of Protein Domains, Current Bioinformatics 2 (2007) 113-131.

[57] Holland T.A., Veretnik S., Shindyalov I.N., Bourne P.E., Partitioning protein structures into domains: why is it so difficult? J Mol Biol 361 (2006) 562-590.

[58] Ponting C.P., Russell R.R., The natural history of protein domains, Annu Rev Biophys Biomol Struct 31 (2002) 45-71.

[59] Holm L., Sander C., Parser for protein folding units, Proteins 19 (1994) 256-268.

[60] Siddiqui A.S., Barton G.J., Continuous and discontinuous domains: an algorithm for the automatic generation of reliable protein domain definitions, Protein Sci 4 (1995) 872-884.

[61] Dengler U., Siddiqui A.S., Barton G.J., Protein structural domains: analysis of the 3Dee domains database, Proteins 42 (2001) 332-344.

[62] Siddiqui A.S., Dengler U., Barton G.J., 3Dee: a database of protein structural domains, Bioinformatics 17 (2001) 200-201.

[63] Swindells M.B., A procedure for detecting structural domains in proteins, Protein Sci 4 (1995) $103-112$.

[64] Holm L., Sander C., Dictionary of recurrent domains in protein structures, Proteins 33 (1998) 88-96.

[65] Wernisch L., Hunting M., Wodak S.J., Identification of structural domains in proteins by a graph heuristic, Proteins 35 (1999) 338-352.

[66] Xu Y., Xu D., Gabow H.N., Protein domain decomposition using a graph-theoretic approach, Bioinformatics 16 (2000) 1091-1104.

[67] Guo J.T., Xu D., Kim D., Xu Y., Improving the performance of DomainParser for structural domain partition using neural network, Nucleic Acids Res 31 (2003) 944-952.

[68] Alexandrov N., Shindyalov I., PDP: protein domain parser, Bioinformatics 19 (2003) 429-430.

[69] Zhou H., Xue B., Zhou Y., DDOMAIN: Dividing structures into domains using a normalized domaindomain interaction profile, Protein Sci 16 (2007) 947-955.

[70] Lesk A.M., Rose G.D., Folding units in globular proteins, Proc Natl Acad Sci U S A 78 (1981) 43044308.

[71] Sowdhamini R., Blundell T.L., An automatic method involving cluster analysis of secondary structures for the identification of domains in proteins, Protein Sci 4 (1995) 506-520.

[72] Tsai C.J., Nussinov R., Hydrophobic folding units derived from dissimilar monomer structures and their 
interactions, Protein Sci 6 (1997) 24-42.

[73] Pugalenthi G., Archunan G., Sowdhamini R., DIAL: a web-based server for the automatic identification of structural domains in proteins, Nucleic Acids Res 33 (2005) W130-132.

[74] Wodak S.J., Janin J., Location of structural domains in protein, Biochemistry 20 (1981) 6544-6552.

[75] Wetlaufer D.B., Nucleation, rapid folding, and globular intrachain regions in proteins, Proc Natl Acad Sci U S A 70 (1973) 697-701.

[76] Wetlaufer D.B., Folding of protein fragments, Adv Protein Chem 34 (1981) 61-92.

[77] Gelly J.C., de Brevern A.G., Hazout S., 'Protein Peeling': an approach for splitting a 3D protein structure into compact fragments, Bioinformatics 22 (2006) 129-133.

[78] Sali A., Blundell T.L., Definition of general topological equivalence in protein structures. A procedure involving comparison of properties and relationships through simulated annealing and dynamic programming, $\mathrm{J}$ Mol Biol 212 (1990) 403-428.

[79] Kolinski A., Bujnicki J.M., Generalized protein structure prediction based on combination of foldrecognition with de novo folding and evaluation of models, Proteins 61 Suppl 7 (2005) 84-90.

[80] Hardin C., Pogorelov T.V., Luthey-Schulten Z., Ab initio protein structure prediction, Curr Opin Struct Biol 12 (2002) 176-181.

[81] Karplus K., Katzman S., Shackleford G., Koeva M., Draper J., Barnes B., Soriano M., Hughey R., SAM-T04: what is new in protein-structure prediction for CASP6, Proteins 61 Suppl 7 (2005) 135-142.

[82] Vasquez M., Modeling side-chain conformation, Curr Opin Struct Biol 6 (1996) 217-221.

[83] Dunbrack R.L., Jr., Gerloff D.L., Bower M., Chen X., Lichtarge O., Cohen F.E., Meeting review: the Second meeting on the Critical Assessment of Techniques for Protein Structure Prediction (CASP2), Asilomar, California, December 13-16, 1996, Fold Des 2 (1997) R27-42.

[84] Dunbrack R.L., Jr., Rotamer libraries in the 21st century, Curr Opin Struct Biol 12 (2002) 431-440.

[85] Schrauber H., Eisenhaber F., Argos P., Rotamers: to be or not to be? An analysis of amino acid sidechain conformations in globular proteins, J Mol Biol 230 (1993) 592-612.

[86] De Maeyer M., Desmet J., Lasters I., All in one: a highly detailed rotamer library improves both accuracy and speed in the modelling of sidechains by dead-end elimination, Fold Des 2 (1997) 53-66.

[87] Lovell S.C., Word J.M., Richardson J.S., Richardson D.C., The penultimate rotamer library, Proteins 40 (2000) 389-408.

[88] Koehl P., Delarue M., Application of a self-consistent mean field theory to predict protein side-chains conformation and estimate their conformational entropy, J Mol Biol 239 (1994) 249-275.

[89] Bower M.J., Cohen F.E., Dunbrack R.L., Jr., Prediction of protein side-chain rotamers from a backbone-dependent rotamer library: a new homology modeling tool, J Mol Biol 267 (1997) 1268-1282.

[90] Dunbrack R.L., Jr., Cohen F.E., Bayesian statistical analysis of protein side-chain rotamer preferences, Protein Sci 6 (1997) 1661-1681.

[91] Dunbrack R.L., Jr., Karplus M., Backbone-dependent rotamer library for proteins. Application to sidechain prediction, J Mol Biol 230 (1993) 543-574.

[92] Canutescu A.A., Shelenkov A.A., Dunbrack R.L., Jr., A graph-theory algorithm for rapid protein sidechain prediction, Protein Sci 12 (2003) 2001-2014.

[93] Eyal E., Najmanovich R., McConkey B.J., Edelman M., Sobolev V., Importance of solvent accessibility and contact surfaces in modeling side-chain conformations in proteins, J Comput Chem 25 (2004) 712-724.

[94] Xiang Z., Honig B., Extending the accuracy limits of prediction for side-chain conformations, J Mol Biol 311 (2001) 421-430.

[95] Xu J., Rapid side-chain prediction via tree decomposition., RECOMB, 2005.

[96] Hartmann C., Antes I., Lengauer T., IRECS: a new algorithm for the selection of most probable ensembles of side-chain conformations in protein models, Protein Sci 16 (2007) 1294-1307.

[97] Noguchi T., Akiyama Y., PDB-REPRDB: a database of representative protein chains from the Protein 
Data Bank (PDB) in 2003, Nucleic Acids Res 31 (2003) 492-493.

[98] Noguchi T., Matsuda H., Akiyama Y., PDB-REPRDB: a database of representative protein chains from the Protein Data Bank (PDB), Nucleic Acids Res 29 (2001) 219-220.

[99] Berman H.M., Westbrook J., Feng Z., Gilliland G., Bhat T.N., Weissig H., Shindyalov I.N., Bourne P.E., The Protein Data Bank, Nucleic Acids Res 28 (2000) 235-242.

[100] Porto M., Bastolla U., Roman H.E., Vendruscolo M., Reconstruction of protein structures from a vectorial representation, Phys Rev Lett 92 (2004) 218101.

[101] Hubbard S.J., Thornton J.M., 'NACCESS', Computer Program, Department of

Biochemistry and Molecular Biology, University College London., 1993.

[102] Murzin A.G., Brenner S.E., Hubbard T., Chothia C., SCOP: a structural classification of proteins database for the investigation of sequences and structures, J Mol Biol 247 (1995) 536-540.

[103] Michie A.D., Orengo C.A., Thornton J.M., Analysis of domain structural class using an automated class assignment protocol, J Mol Biol 262 (1996) 168-185.

[104] Cheng J., Baldi P., Improved residue contact prediction using support vector machines and a large feature set, BMC Bioinformatics 8 (2007) 113.

[105] Samanta U., Pal D., Chakrabarti P., Packing of aromatic rings against tryptophan residues in proteins, Acta Crystallogr D Biol Crystallogr 55 (1999) 1421-1427.

[106] Samanta U., Pal D., Chakrabarti P., Environment of tryptophan side chains in proteins, Proteins 38 (2000) 288-300.

[107] Meurisse R., Brasseur R., Thomas A., Aromatic side-chain interactions in proteins. Near- and farsequence His-X pairs, Biochim Biophys Acta 1649 (2003) 85-96.

[108] Gelly J.C., Etchebest C., Hazout S., de Brevern A.G., Protein Peeling 2: a web server to convert protein structures into series of protein units, Nucleic Acids Res 34 (2006) W75-78.

[109] Chothia C., The nature of the accessible and buried surfaces in proteins, J Mol Biol 105 (1976) 1-12.

[110] Thomas A., Meurisse R., Brasseur R., Aromatic side-chain interactions in proteins. II. Near- and farsequence Phe-X pairs, Proteins 48 (2002) 635-644.

[111] Thomas A., Meurisse R., Charloteaux B., Brasseur R., Aromatic side-chain interactions in proteins. I. Main structural features, Proteins 48 (2002) 628-634.

[112] Bhattacharyya R., Chakrabarti P., Stereospecific interactions of proline residues in protein structures and complexes, J Mol Biol 331 (2003) 925-940.

[113] Chakrabarti P., Chakrabarti S., C--H.O hydrogen bond involving proline residues in alpha-helices, J Mol Biol 284 (1998) 867-873.

[114] Eswar N., Ramakrishnan C., Secondary structures without backbone: an analysis of backbone mimicry by polar side chains in protein structures, Protein Eng 12 (1999) 447-455.

[115] Eswar N., Ramakrishnan C., Deterministic features of side-chain main-chain hydrogen bonds in globular protein structures, Protein Eng 13 (2000) 227-238.

[116] Blundell T.L., Sibanda B.L., Montalvao R.W., Brewerton S., Chelliah V., Worth C.L., Harmer N.J., Davies O., Burke D., Structural biology and bioinformatics in drug design: opportunities and challenges for target identification and lead discovery, Philos Trans R Soc Lond B Biol Sci 361 (2006) 413-423.

[117] Kamat A.P., Lesk A.M., Contact patterns between helices and strands of sheet define protein folding patterns, Proteins 66 (2007) 869-876.

[118] Holm L., Sander C., Protein structure comparison by alignment of distance matrices, J Mol Biol 233 (1993) 123-138.

[119] de Melo R.C., Lopes C.E., Fernandes F.A., Jr., da Silveira C.H., Santoro M.M., Carceroni R.L., Meira W., Jr., Araujo Ade A., A contact map matching approach to protein structure similarity analysis, Genet Mol Res 5 (2006) 284-308.

[120] Rainey J.K., Goh M.C., Statistically based reduced representation of amino acid side chains, J Chem Inf Comput Sci 44 (2004) 817-830. 
[121] Gromiha M.M., Selvaraj S., Inter-residue interactions in protein folding and stability, Prog Biophys Mol Biol 86 (2004) 235-277.

[122] Lesk A.M., Chothia C., Solvent accessibility, protein surfaces, and protein folding, Biophys J 32 (1980) $35-47$.

[123] Etchebest C., Benros C., Bornot A., Camproux A.C., de Brevern A.G., A reduced amino acid alphabet for understanding and designing protein adaptation to mutation, European Biophysics Journal 36 (2007) 10591069.

[124] Meurisse R., Brasseur R., Thomas A., Aromatic side-chain interactions in proteins: near- and farsequence Tyr-X pairs, Proteins 54 (2004) 478-490.

[125] Srinivasan N., Sowdhamini R., Ramakrishnan C., Balaram P., Conformations of disulfide bridges in proteins, Int J Pept Protein Res 36 (1990) 147-155.

[126] Sowdhamini R., Srinivasan N., Shoichet B., Santi D.V., Ramakrishnan C., Balaram P., Stereochemical modeling of disulfide bridges. Criteria for introduction into proteins by site-directed mutagenesis, Protein Eng 3 (1989) 95-103.

[127] Vinayagam A., Pugalenthi G., Rajesh R., Sowdhamini R., DSDBASE: a consortium of native and modelled disulphide bonds in proteins, Nucleic Acids Res 32 (2004) D200-202.

[128] Thangudu R.R., Sharma P., Srinivasan N., Offmann B., Analycys: a database for conservation and conformation of disulphide bonds in homologous protein domains, Proteins 67 (2007) 255-261.

[129] Thangudu R.R., Vinayagam A., Pugalenthi G., Manonmani A., Offmann B., Sowdhamini R., Native and modeled disulfide bonds in proteins: knowledge-based approaches toward structure prediction of disulfiderich polypeptides, Proteins 58 (2005) 866-879.

[130] Mitchell J.B., Nandi C.L., McDonald I.K., Thornton J.M., Price S.L., Amino/aromatic interactions in proteins: is the evidence stacked against hydrogen bonding? J Mol Biol 239 (1994) 315-331.

[131] Brocchieri L., Karlin S., How are close residues of protein structures distributed in primary sequence? Proc Natl Acad Sci U S A 92 (1995) 12136-12140.

[132] Shapovalov M.V., Dunbrack R.L., Jr., Statistical and conformational analysis of the electron density of protein side chains, Proteins 66 (2007) 279-303.

[133] Matthews B.W., X-ray crystallographic studies of proteins, Annu. Rev. Phys.Chem 27 (1976) 493-523.

[134] Hazout S., Entropy-derived measures for assessing the accuracy of N-state prediction algorithms., in: de Brevern A.G. (Ed.), Recent Advances in Structural Bioinformatics, Research signpost, Trivandrum, India, 2007, p. in press.

[135] DeLano W.L.T., The PyMOL Molecular Graphics System, DeLano Scientific, San Carlos, CA, USA. http://www.pymol.org (2002). 